Research Article

\title{
Experimental Study on Comprehensive Real-Time Methods to Determine Geological Condition of Rock Mass along the Boreholes while Drilling in Underground Coal Mines
}

\author{
Ganggang Niu, ${ }^{1,2}$ Kai Zhang $\mathbb{D}^{1,2}$ Bosong Yu, ${ }^{1,2}$ Yanlong Chen $\mathbb{D}^{1,2}$ Yu Wu ${ }^{10},{ }^{1,2}$ \\ and Jiangfeng Liu ${ }^{1,2}$ \\ ${ }^{1}$ State Key Laboratory for Geomechanics \& Deep Underground Engineering, China University of Mining \& Technology, \\ Xuzhou 221116, Jiangsu, China \\ ${ }^{2}$ School of Mechanics \& Civil Engineering, China University of Mining \& Technology, Xuzhou 221116, Jiangsu, China \\ Correspondence should be addressed to Kai Zhang; kzhang@cumt.edu.cn
}

Received 2 August 2019; Accepted 5 November 2019; Published 26 November 2019

Academic Editor: Salvatore Russo

Copyright (C) 2019 Ganggang Niu et al. This is an open access article distributed under the Creative Commons Attribution License, which permits unrestricted use, distribution, and reproduction in any medium, provided the original work is properly cited.

The geological condition is essential for mining design and disaster control in underground coal mines. The present research focuses on the real-time assessment method on rock mass condition during drilling boreholes. In situ comprehensive experiments were carried out using three methods, which are measurement while drilling (MWD) system, vibration measurement while drilling (VMWD) system, and borehole camera detecting system. In the MWD system, the operating parameters of the drilling machine were recorded, and a dimensionless index $I_{\mathrm{d}}$ based on the collected parameters was adopted to assess the geological condition along the borehole. The results show that the state of rock mass can be well classified using the MWD system for both the cross-layer and in-seam boreholes. In the VMWD system, the vibration of the drilling bit was monitored, and the signal was analyzed in both time domain and frequency domain. The results indicate that the rock mass condition can be quantitatively evaluated using the mean square value of the signal and qualitatively estimated using the energy of the spectrum. In the borehole camera system, the photos of the rock mass along the borehole could be well captured, and the identified rock mass condition was used to verify the results of the MWD and VMWD systems. Comprehensive compassion between the results from the three systems shows that all the methods can give valuable information for the geological condition, and the outcomes of the different methods are generally comparable. For practical purposes, the advantages of the involved three detecting systems are discussed.

\section{Introduction}

The information of rock mass conditions is very important for rock engineering. There are a lot of methods to detect the rock conditions, such as geological radar [1-3] and electrical survey system [4]. Data interpretation is the critical and difficult work for these methods and the results are indirect. As an alternative, detection via drilling boreholes may give more reliable results. Therefore, in the underground coal mines in China, a lot of boreholes are drilled to probe water and methane distribution $[5,6]$ and control the failure of rock layers [7]. During the excavation of roadways in the coal mines, drilling advanced survey boreholes has been a compulsive operating procedure to prevent geological hazards.

The response of the drilling machine relates closely with the condition of rock mass; for example, in the hard rock, the drilling rate will decrease while the vibration of the machine will increase. The skilled operators can always judge the geological conditions based on the operating parameters of the drilling machine. However, the judgment of the operators is subjective and may not be reliable. Therefore, it is of great significance for the underground coal mine safety if the information such as the state of surrounding rocks can be interpreted automatically from the drilling process of boreholes. That is the objective of the present study. 
Currently, there are two methods to acquire information during drilling boreholes, which are measurement while drilling (MWD) system and logging while drilling (LWD) system. In the MWD system, the operating parameters of the drifter are recorded, such as drilling rate, rotate pressure, and push force [8-16]. Then, the condition of the rock mass and state of the drilling machine can be assessed based on mechanical principles or data analysis algorithm. A lot of researchers have studied MWD system by experiments, numerical simulation, and mechanical models. In the experiments, Capik et al. [17] and Kahraman [18] studied the variation of drilling rate on different rock specimens in laboratory tests. Patel [19] and Tan et al. [20] determined the rock layers based on the monitored parameters of the rig in situ. The experimental results showed that the response of rig has clear relation with the property of rock mass. In the numerical simulation, some scholars simulated the drilling process using Finite Element Method [21, 22] or Discrete Element Method [23]. In the simulation, more complicated conditions can be considered, such as the initial stress and properties of the rock mass. In mechanical models, specific energy is widely used to relate the parameters of rig to the properties of rock; however, the specific energy is dependent on the applied push force and may only give relative results [24-29]. Zhang et al. [30] proposed an index for the rock drillability based on dimension analysis method and identified different kinds of rock mass in the in situ tests. Some researchers [31-34] use intelligent algorithms, such as Artificial Neural Network, to identify the state of rock mass.

The LWD system is generally used for petroleum exploitation. In the system, logging instruments are used for recording the physical parameters of rock mass, such as gamma ray, resistivity, and volume density. The acquired information was used to evaluate the strata information and distribution of oil resource [35-38]. However, the LWD technology is rarely used in underground coal mines. The main reason is that the application of the system is timeconsuming and there is not enough room in the underground to implement the testing. Most importantly, the information provided by the LWD system is seldom used in mining activities.

To sum up, the MWD system has great potential to be applied in underground coal mines and provides valuable information on the geological condition. However, the current research on the system is not sufficient, and the application of the system in coal mines is limited. In the present study, in situ comprehensive experiments are carried out using a self-designed MWD system in an underground coal mine, together with vibration measuring and borehole camera detecting systems. Real-time classifying methods for rock mass condition are proposed and discussed based on the different systems. The results can provide a basis for obtaining geological conditions quickly and reliably in underground coal mines.

\section{Experimental Equipment}

Three pieces of equipment are used in the present research to analyze the rock mass geological conditions along the boreholes, which are measurement while drilling (MWD) system, vibration measurement while drilling (VMWD) system, and borehole camera system.

2.1. Structure of a Typical Underground Drilling Machine. At present, the full hydro drilling machines are widely used in underground coal mines in China. The typical structure of the machine is shown in Figure 1. The power of the full hydro drilling machine mainly comes from two parts. The first part is the power head composed of a hydraulic motor and gearbox, which provides the rotary torque for the drill bit. The second part is a feed mechanism composed of a hydraulic cylinder under the guide rail, which provides the feed pressure for the drill bit. There is a pump station to provide high-pressure oil for the hydraulic motor and cylinder. The operation procedure of the drilling machine is as follows: (1) connect water or compressed air pipe to the drill rods, until the water or gas flows through the rods and comes out of the borehole; (2) provide high-pressure oil to the hydraulic motor and cylinder, and the drill bit will rotate and move toward the bottom of the borehole.

2.2. MWD System. The MWD system (Figure 2) is developed by the authors, which composed of a recorder, a battery, and four sensors. As for the application in underground coal mines, the recorder and battery are explosion proof design. The sensors include two pressure sensors for monitoring the pressure of hydraulic motor and cylinders, one hall element for recording the rotation rate of the drilling rods and one displacement sensor for logging the drilling rate. The main parameters of the MWD system are listed in Table 1.

2.3. VMWD System. The VMWD system is composed of a handheld computer and measuring component. The two parts connect through Wi-Fi. The parameters of the measuring component are configured by the handheld computer. The measuring component operates in the borehole and should be installed just behind the drilling bit. The measuring component has two parts: sensors and specific rods. The sensors include a three-component acceleration sensor for recording the vibration along and perpendicular to the drilling rod, and a gradient meter for capturing the borehole trajectory. The sensors are packaged with battery and memory and then installed inside the specific rods, which are made of nonmagnetic materials to make the sensors working properly. The specific rods connect to the drilling bit at one end and to the general drilling rod at the other end. The layout of the VMWD system is shown in Figure 3.

During drilling the borehole, the sensors work uninterruptedly. After the borehole is finished, the specific rods are retreated and the data of the sensors are transferred to the handheld computer through Wi-Fi.

The main parameters of the VMWD system are listed in Table 2. 


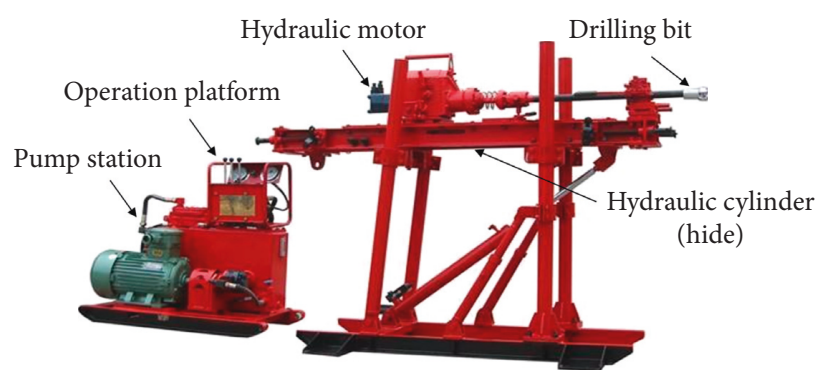

FIgURE 1: Full hydro drilling machine.

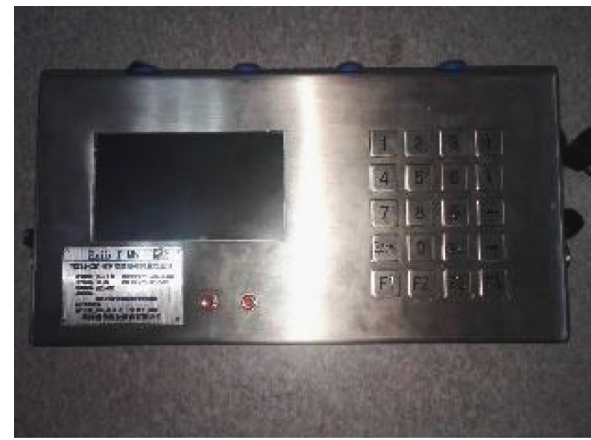

(a)

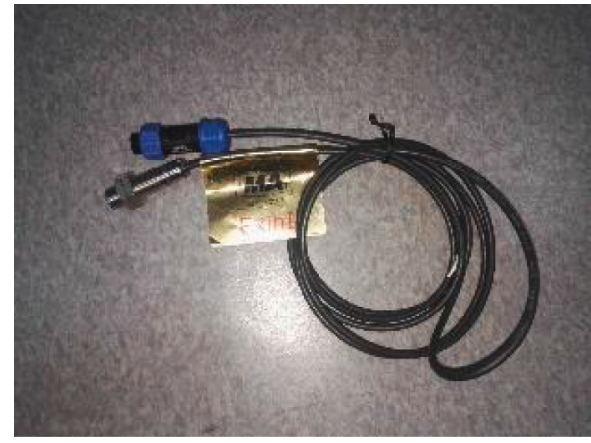

(c)

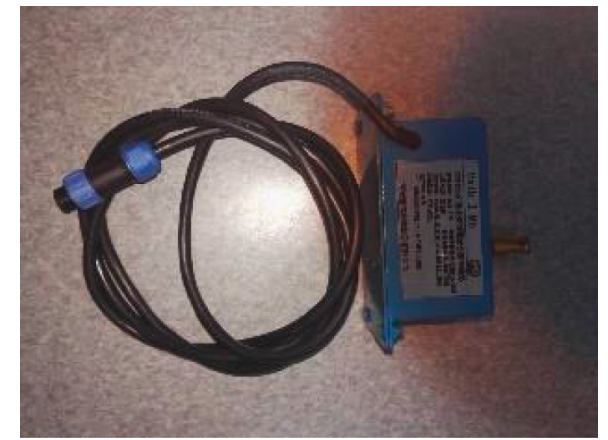

(b)

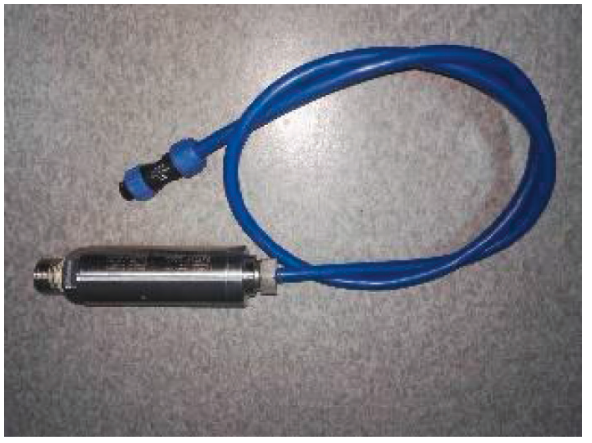

(d)

Figure 2: The MWD system: (a) recorder; (b) displacement sensor; (c) hall sensor; (d) pressure sensor.

TABLE 1: Main parameters of the MWD system.

\begin{tabular}{lc}
\hline Item & Value \\
\hline Maximum channel number & 5 \\
Minimum sampling period & $0.5 \mathrm{~s}$ \\
Overall power consumption & $7.5 \mathrm{watt}$ \\
Data transfer mode & USB or Wi-Fi \\
Battery life per recharging cycle & 8 hours \\
\hline
\end{tabular}

2.4. Borehole Camera System. The borehole camera system (Figure 4) is used to take photos of the surrounding rock of the borehole. It gives visual information for assessing the geological conditions, especially the integrity of rock mass and distribution of faults. The image resolution is $0.1 \mathrm{~mm}$. The implementing process of the camera system is as follows. (1) After the borehole is finished, withdraw the drilling rods from the borehole. (2) Push the camera into the borehole using slender rods, during which the displacement of the

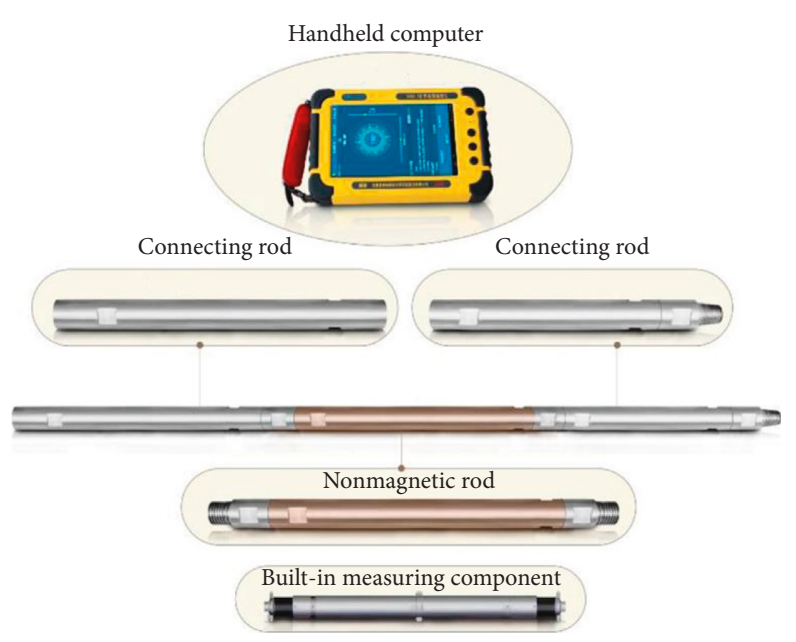

FIgURE 3: Layout of the VMWD system. 
TABLE 2: Main parameters of the VMWD system.

\begin{tabular}{lc}
\hline Item & Value \\
\hline Maximum range of acceleration sensor & $\pm 16 \mathrm{~g}$ \\
Resolution of acceleration sensor & $3.9 \mathrm{mg}$ \\
Sampling frequency & $3200 \mathrm{~Hz}$ \\
Battery life per recharging cycle & 72 hours \\
\hline
\end{tabular}

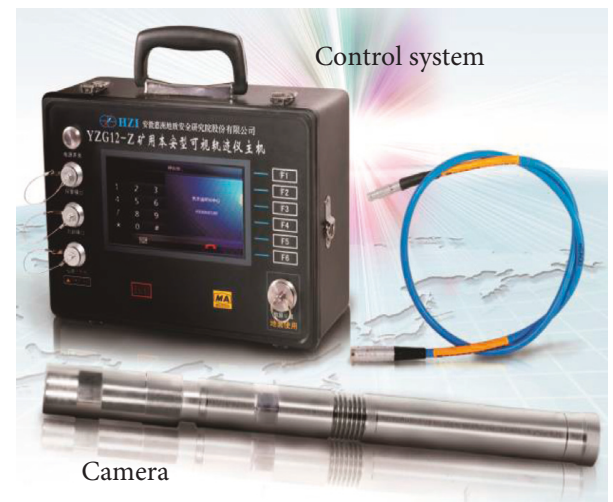

Figure 4: Borehole camera system.

camera and video are recorded. (3) Images at different depth of the borehole are extracted from the video.

\section{Analysis on Experiments of MWD System}

3.1. Test Site and Scenario. The comprehensive experiments are carried out in Yangliu underground coal mine, which is located in Huaibei City, Anhui Province, China. The mine exploits gas and coking coal. The coal mine is a gas outburst mine and also has a water disaster threat. Therefore, a lot of boreholes are drilled in the roadways and around the working faces for extracting methane gas and detecting water distribution.

1075 working faces were selected as the test site. The average thickness of the coal seam is $5.74 \mathrm{~m}$. The roof and floor of the coal seam are composed of sandstone, siltstone, and mudstone. Two kinds of boreholes are tested, which are cross-layer boreholes and in-seam boreholes (Figure 5). Both kinds of boreholes are used to extract methane gas. The cross-layer boreholes are drilled from the roadway in the floor of the coal seam to the roof of the coal seam. Therefore, the cross-layer boreholes will go through different kinds of rock and coal. The in-seam boreholes are drilled in the gate roadway, and the surrounding rock of the boreholes is only coal.

All the boreholes are drilled using the drilling machines with a model number of ZDY3200s. The PDC bits (Figure 6) with a diameter of $73 \mathrm{~mm}$ are used. The drilling process of over 130 boreholes is monitored. Due to the limited space, the results of four boreholes are analyzed in the following. The information of the boreholes is listed in Table 3.

3.2. Typical Testing Results of MWD. Four parameters of the full hydro underground drilling machine were monitored, i.e., rotation pressure (import oil pressure of the rotary motor), feed pressure (import oil pressure of the feed hydraulic cylinder), rotation rate of the rods, and drilling depth. The drilling rate can be calculated using the recorded drilling depth. The layout of the sensors of the MWD system is shown in Figure 7.

A typical monitoring result is shown in Figure 8. In each drilling cycle, the drilling depth is $2 \mathrm{~m}$. As the maximum stock of the oil cylinder is $0.6 \mathrm{~m}$, there are at least four push and return actions in each drilling cycle. In Figure 8, the displacement of the feed hydraulic cylinder decreases during the drilling action.

During the drilling, the operator can adjust the rotation and feed pressure according to the geological condition. When the rock is hard, the rotation and feed pressure will be increased to speed up the drilling rate. However, the pressure should not be increased too high, as the drilling rods may deform and fail. In the present tests, to make it simple, both pressures were not adjusted during the drilling progress. The pressure varies spontaneously as the geological condition changes (Figure 8). At the same time, new drilling bits are used for each borehole. Therefore, the effect of wear of the drilling bit is not involved in the present study.

In order to investigate the sensibility of the monitored parameters, drilling parameters of the two in-seam boreholes (No. 21 and No. 22 in Table 3) are first analyzed. The drilling sites of the two boreholes are approximately $50 \mathrm{~m}$ apart. The drilling machine for borehole No. 22 has a longer service life and lower power than that for borehole No. 21.

Figure 9 shows the parameters of the two boreholes starting from the depth of $21 \mathrm{~m}$ for a duration of $50 \mathrm{~s}$. It can be seen that as the drilling machine has higher power, the rotation and feed pressure are higher in borehole No. 21, as well as the drilling rate. Therefore, it is not suitable to determine the geological condition only based on the values of pressure parameters or drilling rate, when the drilling machines are different.

The monitored parameters of the borehole No. 22 during the entire process are shown in Figure 10. Without any manual intervention, the rotation and feed pressure, as well as the drilling rate, vary greatly as the coal and methane gas condition changes. The variation of the parameters seems to be quite complicated. Then, even for the same drilling machine, it is also difficult to determine the state of rock mass using a single parameter.

3.3. Assessment on Geological Condition of Rock Mass via $M W D$. Generally speaking, the most reliable method for geological exploration is drilling core. However, the method is quite time-consuming and seldom carried out in the underground coal mines. As an alternative, Zhang et al. [30] proposed a method to determine the state of rock mass by using the operating parameters of the drilling machine. Using the method, the geological condition can be assessed in real time, and the amount of the information is abundant as the distribution of the boreholes almost covers the entire range of the mining space. In the method, the authors proposed the rock drillability index $I_{\mathrm{d}}$ based on dimensional analysis theory as follows: 


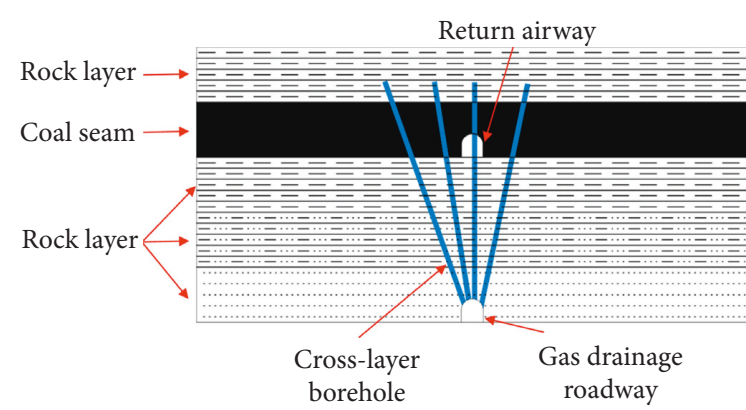

(a)

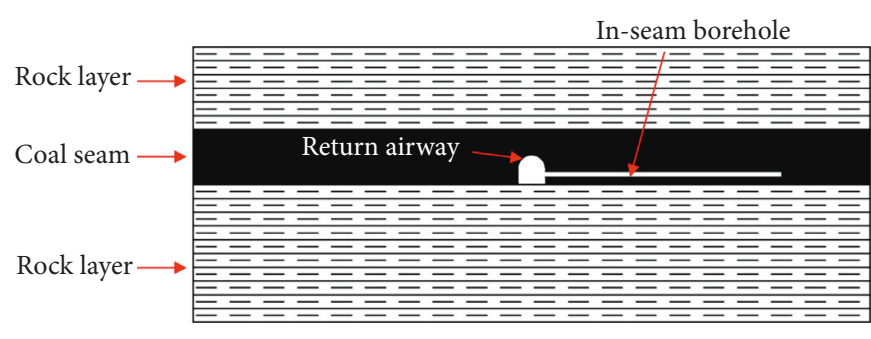

(b)

FIGURE 5: Layout of the boreholes: (a) cross-layer boreholes; (b) in-seam borehole.

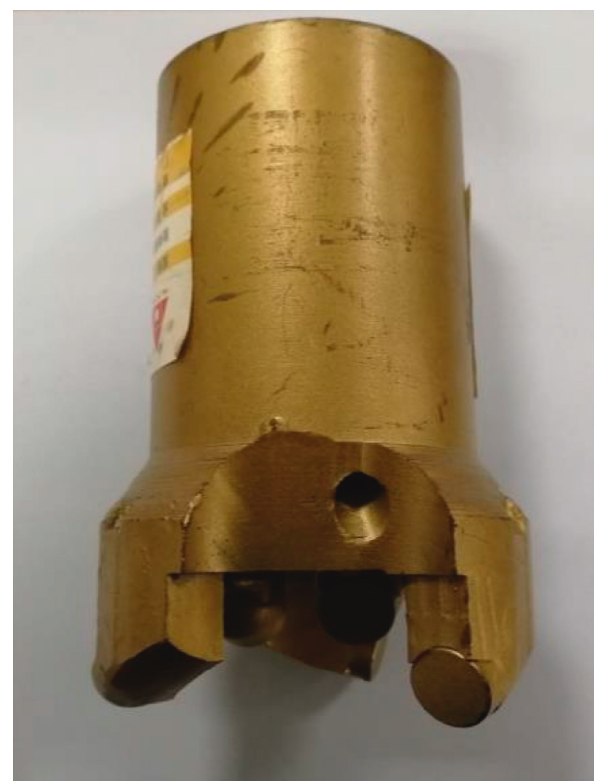

(a)

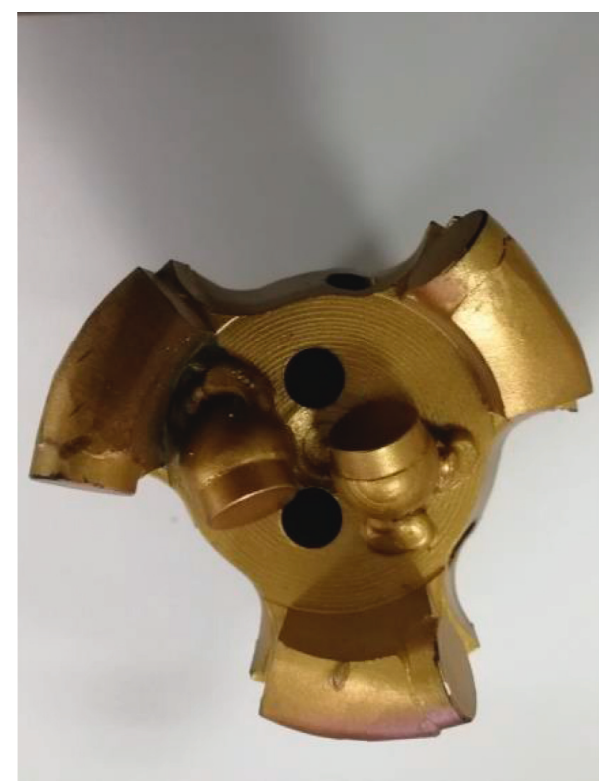

(b)

Figure 6: PDC bit.

TABLE 3: Borehole information.

\begin{tabular}{lcr}
\hline Borehole ID & Orientation $\left(^{\circ}\right)$ & Dip an \\
\hline No. 11 & 49 & 17 \\
No. 12 & 58 & 19 \\
No. 21 & 139 & 7 \\
No. 22 & 225 & 5 \\
& & \\
& & \\
& $I_{\mathrm{d}}=\gamma \pi_{1}^{\alpha} \pi_{2}^{\beta}$,
\end{tabular}

where $\gamma, \alpha$, and $\beta$ are parameters which should be determined by fitting experimental results. Following Zhang et al. [30] research, the values of $\gamma, \alpha$, and $\beta$ are 1,1 , and 0.4 , respectively. $\pi_{1}$ and $\pi_{2}$ are two dimensionless parameters defined as follows:
(1)

$\begin{array}{ll}\text { ngle }\left(^{\circ}\right) & \text { Borehole type } \\ 17 & \begin{array}{c}\text { Cross-layer } \\ \text { Cross-layer } \\ \text { In-seam } \\ \text { In-seam }\end{array} \\ 5 & \left\{\begin{array}{l}\pi_{1}=\frac{D F_{P}}{M}, \\ \pi_{2}=\frac{v}{D \omega},\end{array}\right.\end{array}$

where $D$ is the diameter of the drilling bit, $F_{P}$ is the feeding pressure, $M$ is the torque on the drilling bit, which can be 


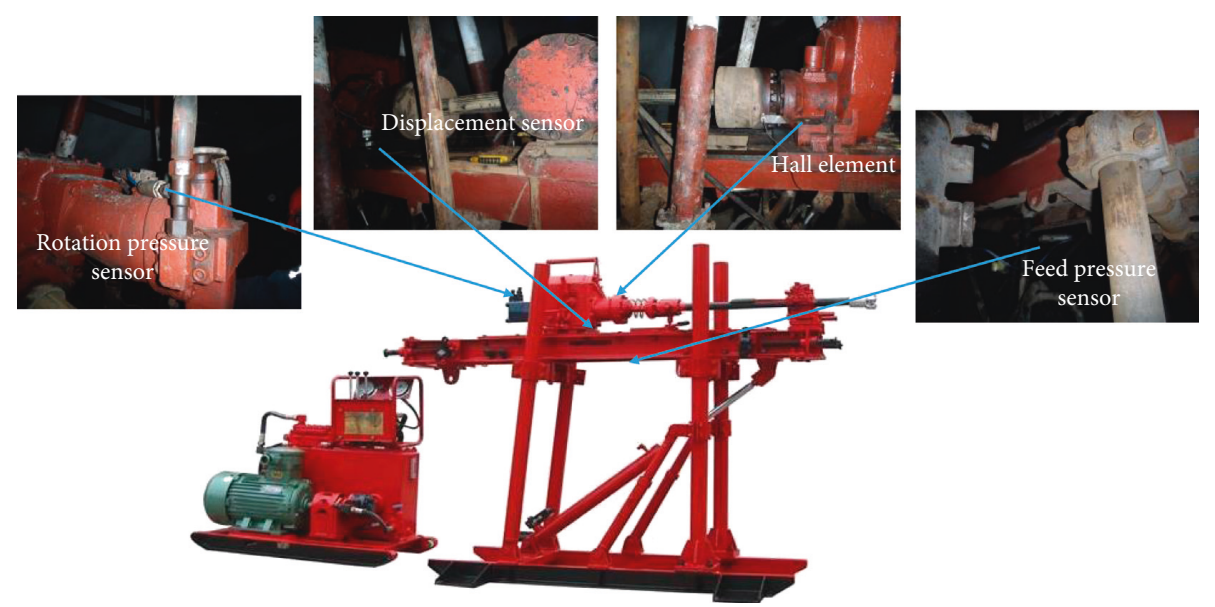

FIGURE 7: Installation of the sensors in MWD system.

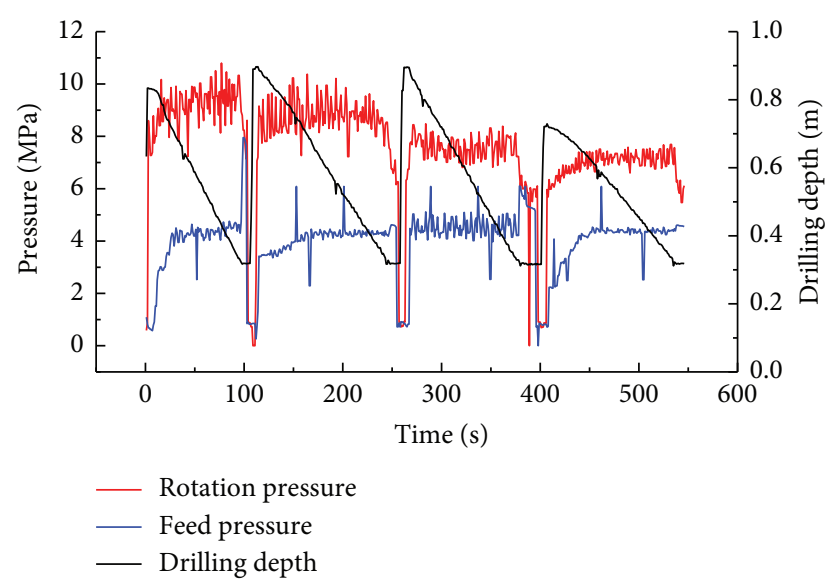

FIgURE 8: Typical curves of parameters during a drilling cycle.
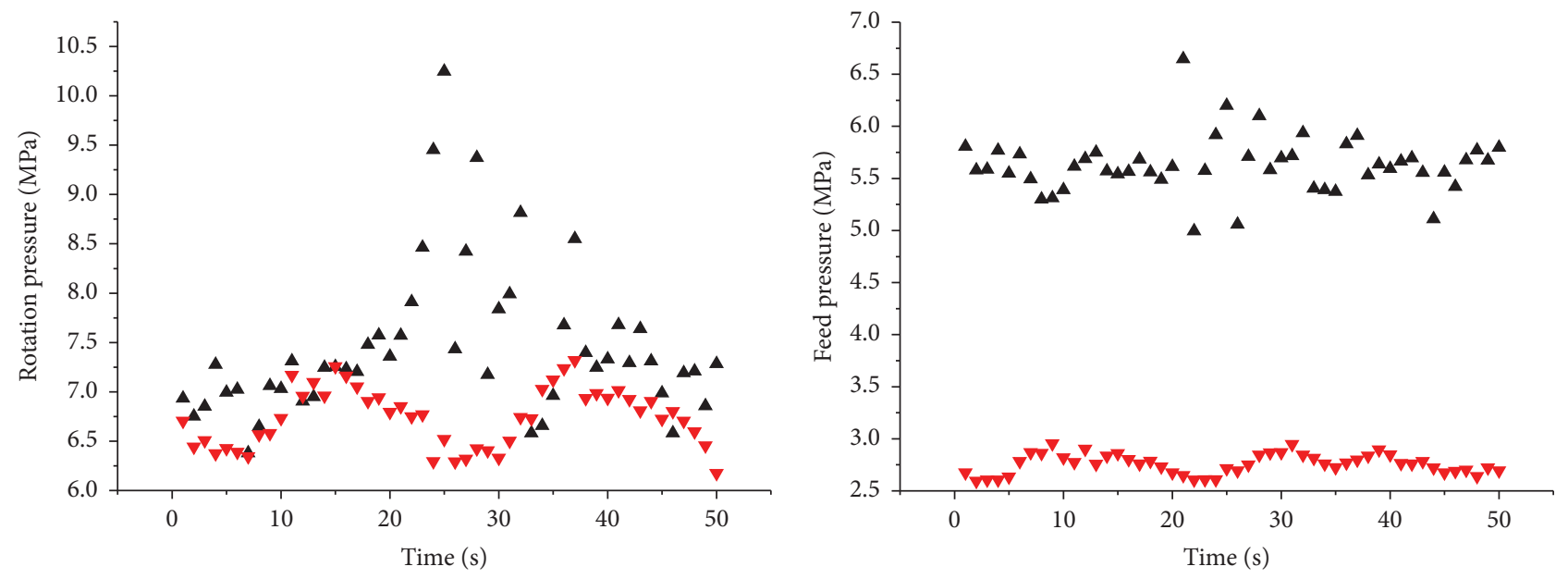

- NO.21

- NO.21

$\checkmark$ NO.22

จ NO.22

(a)

(b)

Figure 9: Continued. 


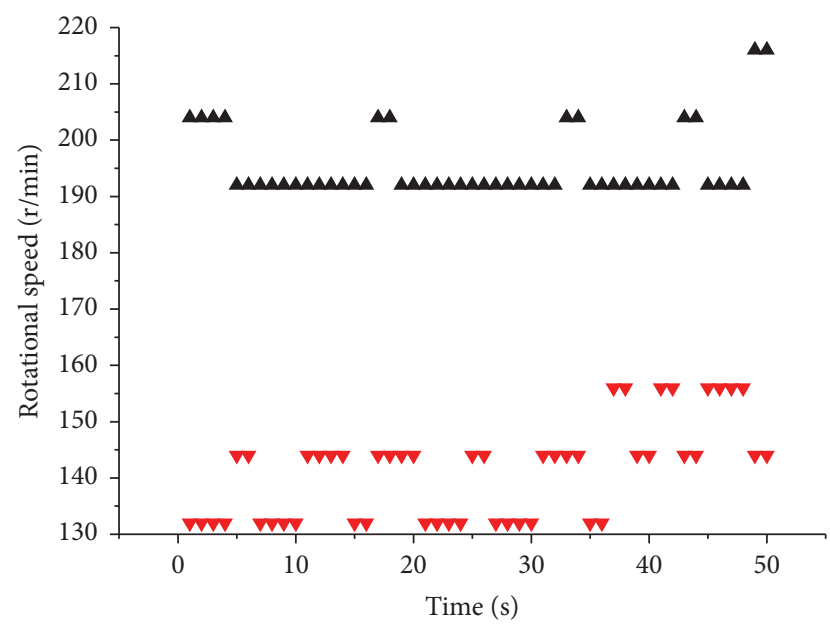

\ $\mathrm{NO} .21$

$\checkmark$ NO.22

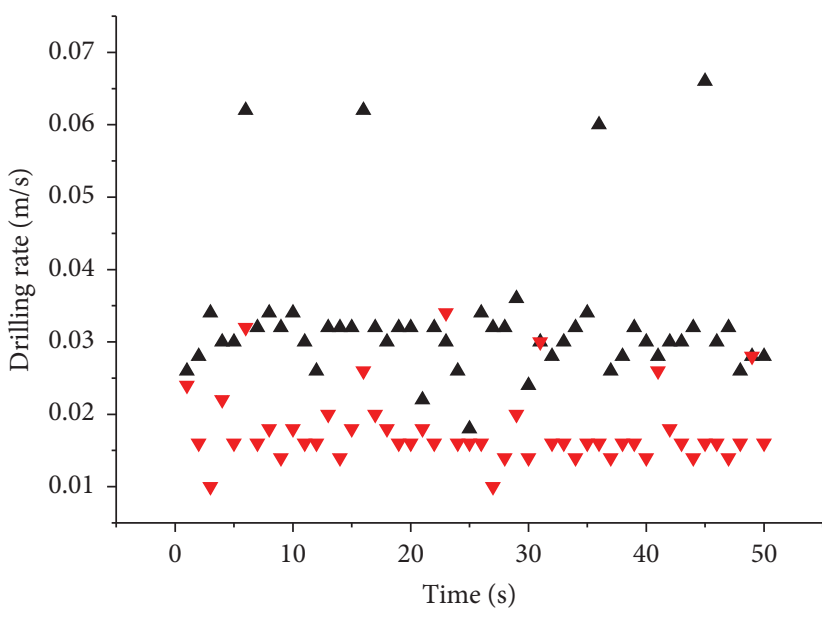

A NO.21

$\checkmark \mathrm{NO} .22$

(c)

(d)

FIGURE 9: Variation of parameters of different boreholes in 50 seconds at the depth of $21 \mathrm{~m}$.

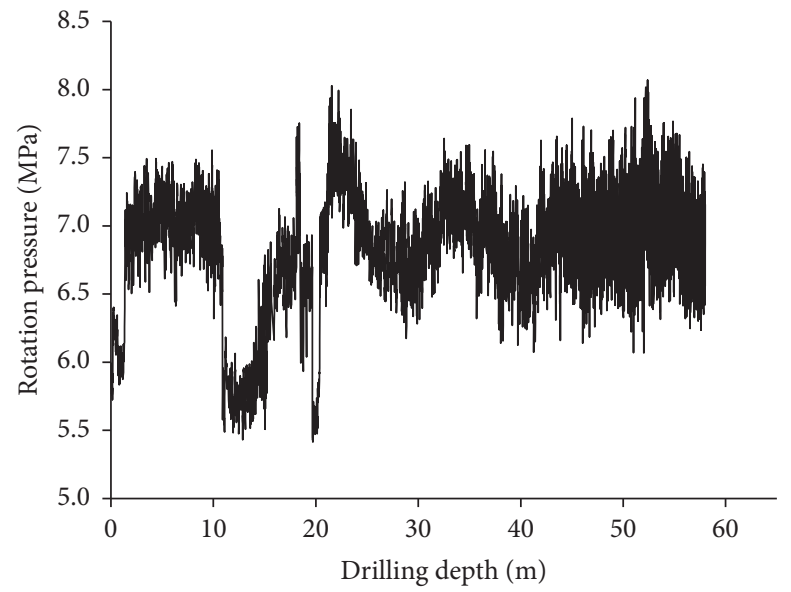

(a)

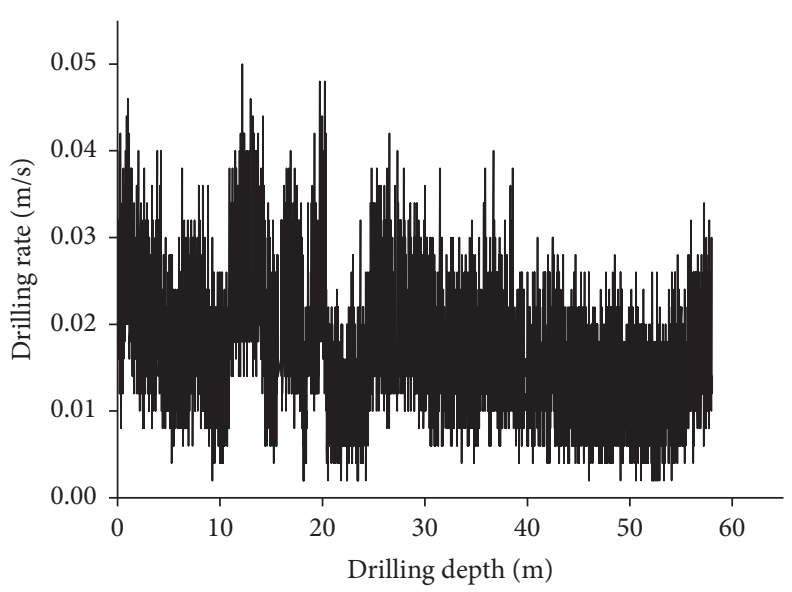

(c)

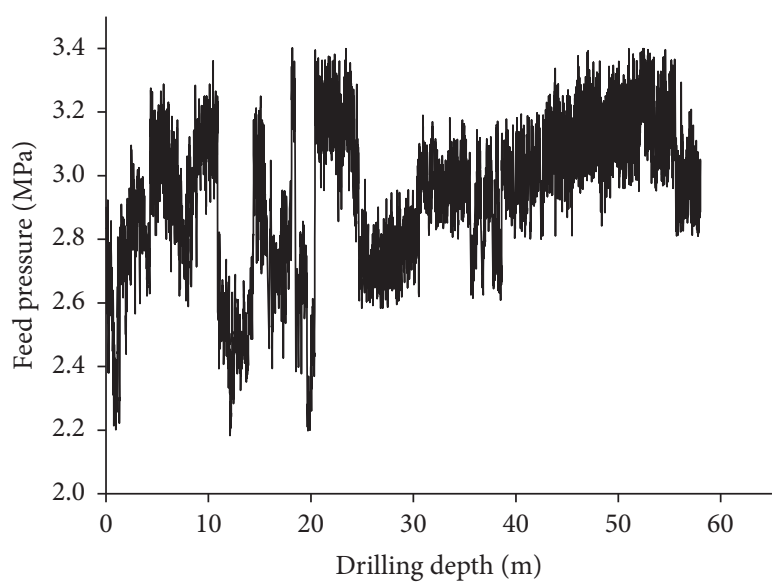

(b)

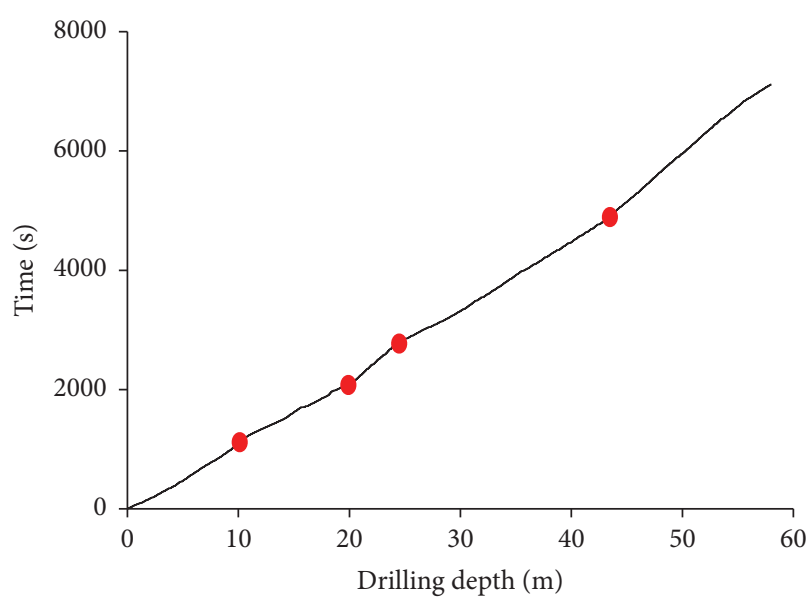

(d)

FIgURE 10: Monitored curves in No. 22 borehole. 
calculated based on the rotation pressure, $v$ is the drilling rate, and $\omega$ is the angular rate of the bit.

The torque of the drilling bit $M$ can be determined as follows. Because of the resistance of hydraulic motor and the friction from the wall of borehole, etc., there is resistance torque when the rods are rotating without cutting the rock. If the resistance torque is denoted by $M_{\mathrm{r}}$, then we get

$$
M=M_{0}-M_{\mathrm{r}} \text {, }
$$

where $M_{0}$ is the output torque of the hydraulic motor, which has a proportional relation with the import pressure of the hydraulic motor $P_{1}$. That is,

$$
M_{0}=k P_{1} \text {, }
$$

where $k$ is a constant and for the hydraulic motor used here is 60, when the unit of $M_{0}$ is $\mathrm{N} \cdot \mathrm{m}$ and $P_{1}$ is $\mathrm{MPa}$.

Then, the resistance torque $M_{\mathrm{r}}$ may be determined by the import pressure of the hydraulic motor $P_{0}$, which is monitored when the bit rotates but without cutting the rock. The equation is as follows:

$$
M_{\mathrm{r}}=k P_{0} .
$$

From the equations (3)-(5), the torque of the drilling bit $M$ can be determined:

$$
M=k\left(P_{1}-P_{0}\right) .
$$

The advantage of equation (2) is that it comprehensively considers all the operating parameters of the drilling machine and may be independent of the machine and geological condition. We applied the method to analyze all of the tested boreholes. Due to the limited space, only the results of boreholes Nos. 11, 12, and 22 (Table 3) are illustrated here. The monitored parameters and the index $I_{\mathrm{d}}$ are shown in Figure 11. From the figures, we can see that as the rotation pressure and feed pressure were not adjusted, if the rock is hard, both pressures increased automatically, while the drilling rate decreased. In Figure 11, the higher value of index $I_{\mathrm{d}}$ represents weaker rock mass or coal.

For the cross-layer borehole No. 11, judged from the rock fragment during drilling, the borehole gets into the coal seam at the depth of approximately $26 \mathrm{~m}$ and gets out of the coal seam at the depth of $32.5 \mathrm{~m}$. As shown in Figure 11(a), before the borehole gets into the coal seam, the value of index $I_{\mathrm{d}}$ increases gradually, which shows that the rock mass around the coal seam floor is weaker. When the borehole is within the coal seam, the value of the index $I_{\mathrm{d}}$ increases to over 3. Thereafter, the index $I_{\mathrm{d}}$ decreases to approximately 2.5 when the borehole is in the coal seam roof.

For the cross-layer borehole No. 12, the borehole gets into the coal seam at the depth of approximately $28 \mathrm{~m}$. As shown in Figure 11(b), before the borehole enters the coal seam, the index $I_{\mathrm{d}}$ varies slightly, which shows relatively homogeneous rock mass along the borehole in the floor. However, at the depth between 20 and $24 \mathrm{~m}$, the rock mass is quite weak and the $I_{\mathrm{d}}$ values are comparable to those of coal.

For the in-seam borehole No. 22 (Figure 11(c)), the monitored pressure is lower than those in the cross-layer boreholes and the $I_{\mathrm{d}}$ values are all over 3 . Compared to those of the cross-layer boreholes, the variation of index $I_{\mathrm{d}}$ is less. It should be noted that at the depth between 10 and $20 \mathrm{~m}$, the $I_{\mathrm{d}}$ values are obviously high. It indicates that the coal in this area may be loose, and the sealing depth should be larger than $20 \mathrm{~m}$ in this borehole. This is consistent with the finding of other researches. By comparing the $I_{\mathrm{d}}$ values with the field record, such as rock fragment and images from the camera system, the surrounding rocks of the tested drilling site can be roughly divided into four categories:

$$
\begin{cases}2.0>I_{\mathrm{d}}, & \text { I, } \\ 2.5>I_{\mathrm{d}} \geq 2.0, & \text { II, } \\ 3.0>I_{\mathrm{d}} \geq 2.5, & \text { III, } \\ I_{\mathrm{d}} \geq 3.0, & \text { IV }\end{cases}
$$

where Class I is for hard rock such as sandstone, Class II is for the rock with strength between sandstone and mudstone, Class III is generally mudstone, and Class IV is for coal or low strength rock mass.

\section{Analysis on Experiments of VMWD}

The VMWD system was installed right behind the drilling bit, as shown in Figure 12. The signals collected by the VMWD system can reflect the working state of the drilling bit. To our knowledge, very few works have been done on the real-time vibration of the drilling bits, especially in underground coal mines. The recorded signals are analyzed in both time domain and frequency domain to study the correlation between the vibration of the bit and geological condition.

4.1. Typical Testing Results of VMWD. The typical recorded vibration signals are shown in Figure 13. In the figure, the directions $x$ and $z$ are in the plane perpendicular to the axes of the drilling rods, and the direction $y$ is the axes of the drilling rods. The purpose of this paper is to study the rock breaking process without considering the friction between drilling rods and the borehole. Therefore, only the signal in the $y$ direction (Figure 13(b)) is analyzed in the following content.

As shown in Figure 13(b), the original vibration signal can be divided into three distinct segments. The first one is the preparation period, i.e., assembling and installation of VMWD. The second one is the drilling period, and the last one is the period of withdrawing drill rods after the completion of the borehole. In the drilling period (segment II), the signal is composed of many groups separated by time intervals. Each signal group represents a drilling cycle as shown in Figure 8 for the MWD system. An algorithm with a threshold can be used to eliminate the time intervals.

\subsection{Assessment on Geological Condition of Rock Mass via VMWD}

4.2.1. Time-Domain Signal Analysis. As the sampling frequency is high in the VMWD system, the amount of the recorded date is huge. The root mean square (RMS) method 

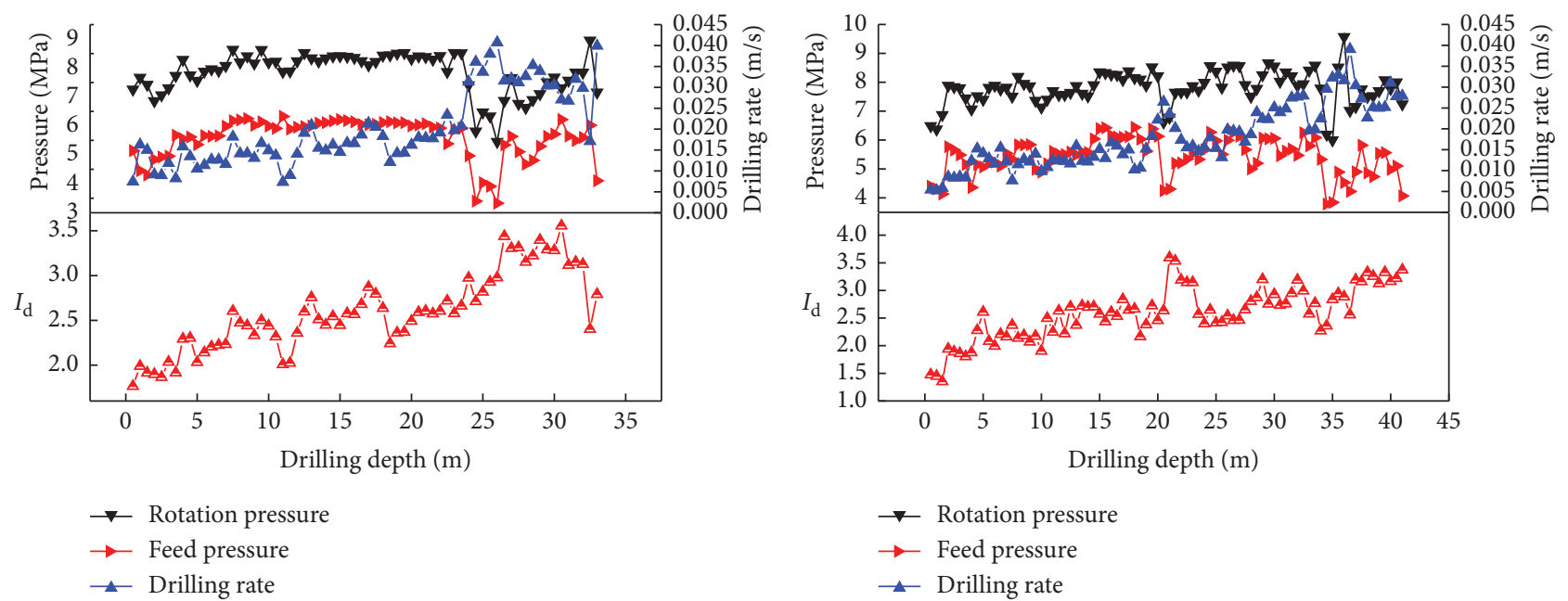

(a)

(b)

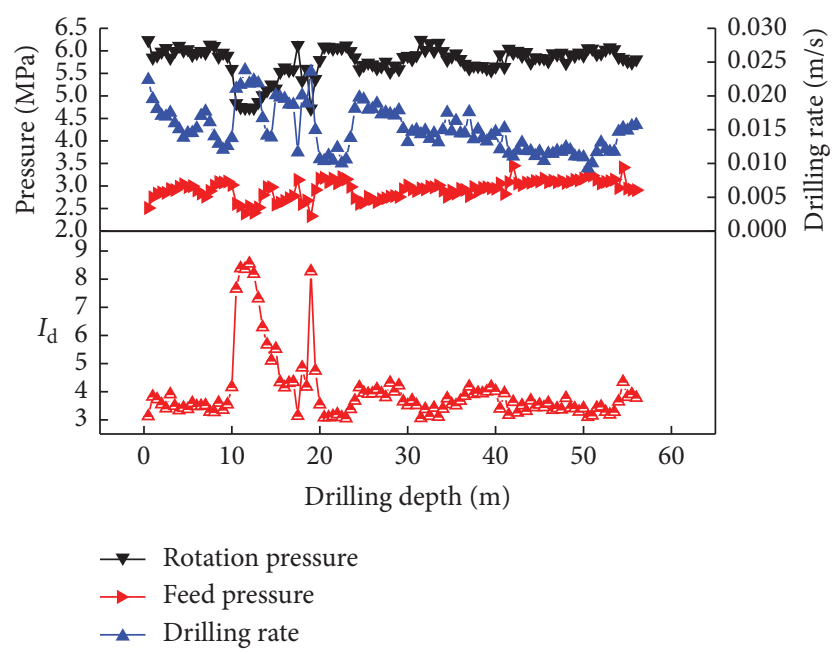

(c)

FIgURE 11: Curves of index $I_{\mathrm{d}}$ of different boreholes: (a) results of cross-layer borehole No. 11; (b) results of cross-layer borehole No. 12; (c) results of in-seam borehole No. 22.

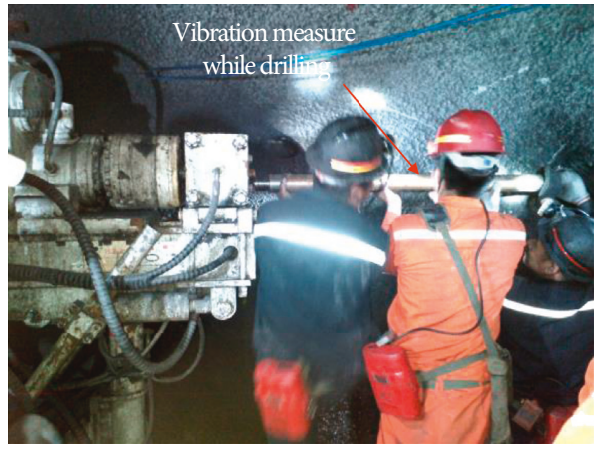

(a)

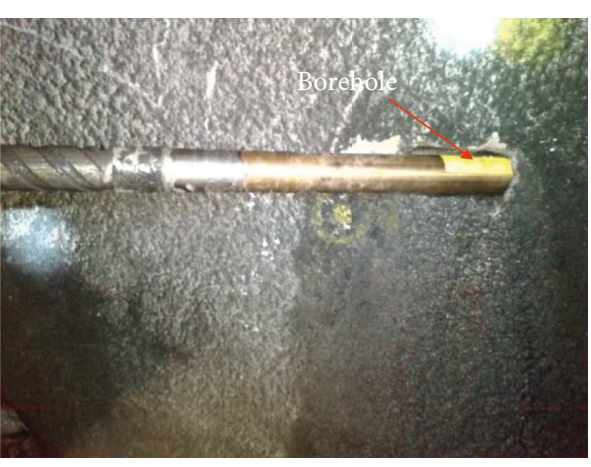

(b)

Figure 12: Field installation of the VMWD system. 


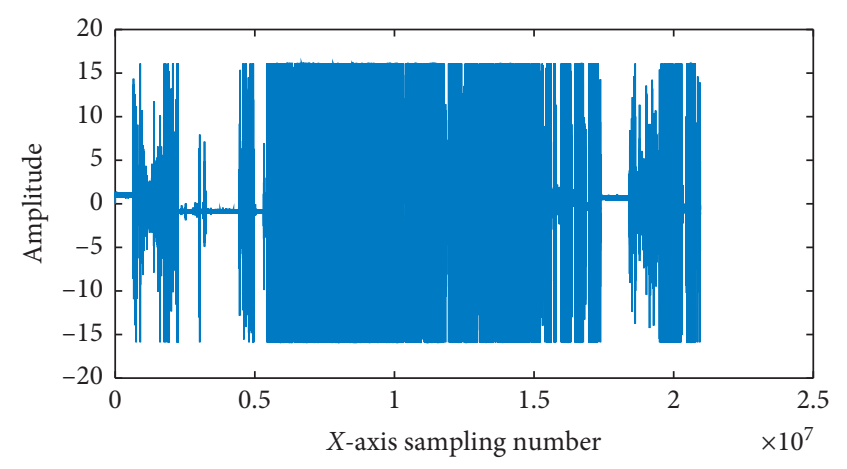

(a)

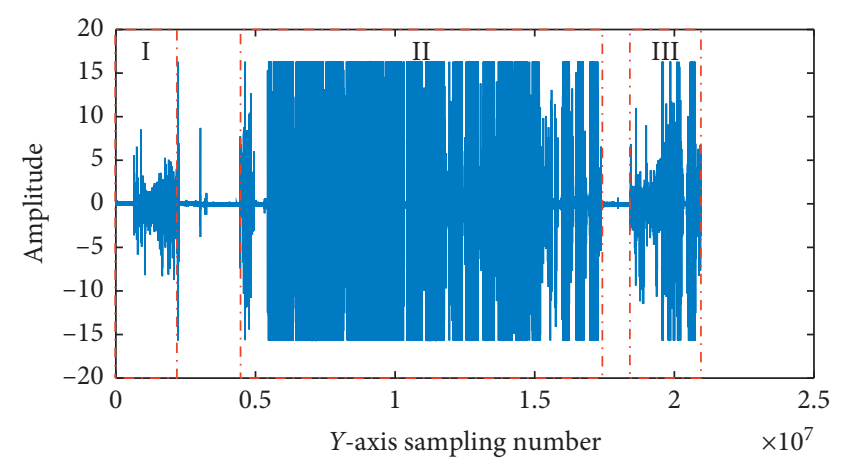

(b)

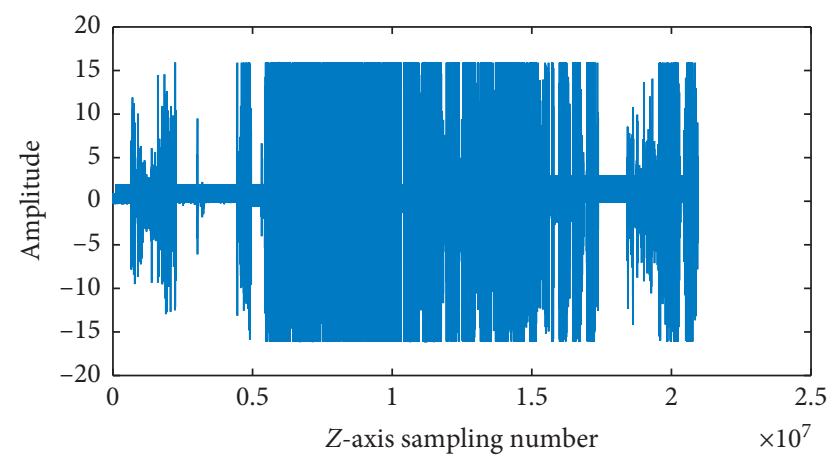

(c)

FIgURe 13: Typical recorded vibration signal: (a) signal in $x$-axis; (b) signal in $y$-axis; (c) signal in $z$-axis.

is adopted here to analyze the vibration signal in the time domain. The mean square value of the signal represents its strength and energy. The average energy of a continuous signal is also called the average power, with a discrete expression on a given time interval as follows:

$$
\psi_{x}^{2}=\frac{1}{T} \int_{0}^{T} x^{2}(t) \mathrm{d} t
$$

where $\psi_{x}$ is the root mean square value, $t$ is the time, $x(t)$ is the vibration signal, and $T$ is the time interval, which is 5 seconds here.

The distribution of RMS values for the cross-layer boreholes is shown in Figure 14. The RMS values present a trend of gradual decrease along the depth of the borehole. According to the experience of the operator, the drilling machine vibrates more intensely while drilling the hard rock. Compared with the results of the MWD system (Figure 11), the RMS values also have a strong correlation with the geological condition. That is, the harder the rock, the higher the RMS value. For the borehole No. 12, within the depth from 20 to $24 \mathrm{~m}$, the RMS values are quite low, which may indicate the existence of broken rock mass. The result is consistent with that from the MWD system.

The distribution of RMS values for the in-seam borehole No. 22 is shown in Figure 15. The RMS values vary from 0.7 to 2.0 , which are much lower than those in the cross-layer boreholes. The reason is that the coal is much weaker than the rock mass in the floor and roof. In the broken part inferred from the results of the MWD system, i.e., from 10 to $20 \mathrm{~m}$, the RMS has lower values.
By comparing the results of VMWD system with those of MWD system and the field observation, the condition of rock mass in the testing site is classified into four categories based on the RMS values of the vibration signal as follows:

$$
\begin{cases}\text { RMS } \geq 5.7, & \text { I, } \\ 5.7>\text { RMS } \geq 4.0, & \text { II, } \\ 4.0>\text { RMS } \geq 3.0, & \text { III, } \\ 3.0>\text { RMS, } & \text { IV, }\end{cases}
$$

where Class I is for hard rock such as sandstone, Class II is for the rock with strength between sandstone and mudstone, Class III is generally mudstone, and Class IV is for coal or low strength rock mass.

4.2.2. Frequency Domain Signal Analysis. The short-time Fourier transform (STFT) is adopted here to conduct frequency domain analysis. In the STFT method, not only the distribution of frequencies but also the amplitude of the specific frequency can be deduced. The amplitude of specific frequency represents the energy occupied by the frequency. Based on a sliding time window, the time-variant characteristic of the signal can be analyzed. The equation of the STFT is as follows:

$$
S(f, t)=\int_{-\infty}^{\infty} e^{-2 \pi j f \tau} f(\tau) \omega(\tau-t) \mathrm{d} \tau,
$$

where $S(f, t)$ is the time-frequency function after transformation, $f(\tau)$ is the amplitude of vibration signal, and 


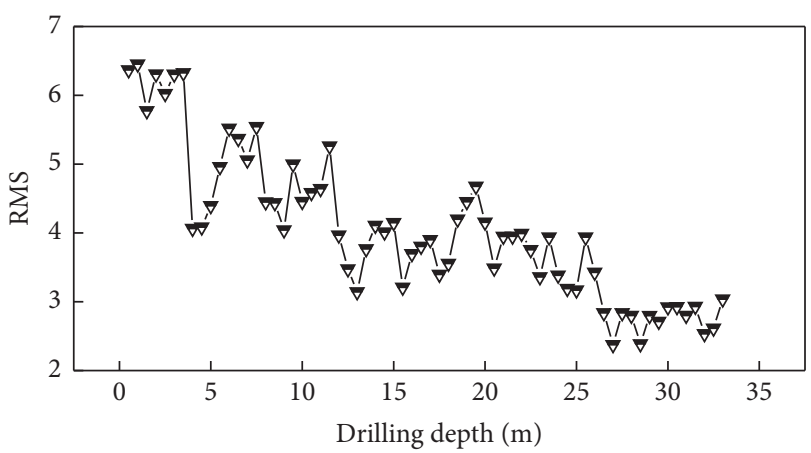

(a)

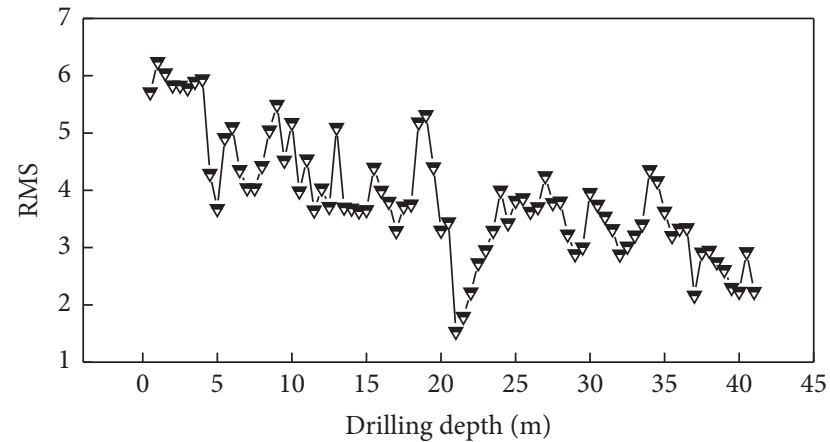

(b)

FIGURE 14: Distribution of RMS values for cross-layer boreholes: (a) borehole No. 11; (b) borehole No. 12.

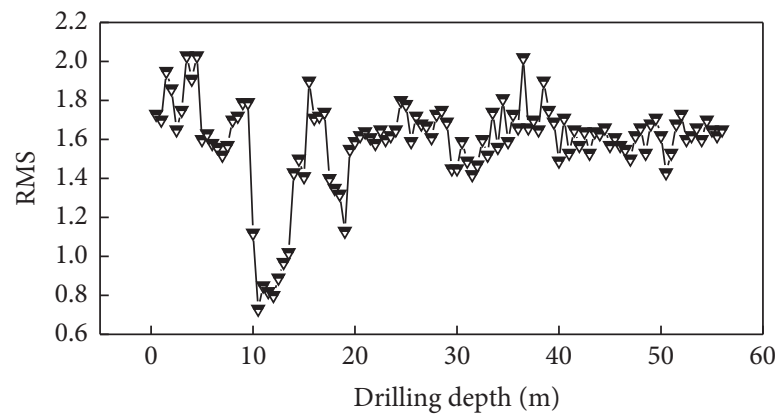

FIGURE 15: Distribution of RMS values for in-seam boreholes.

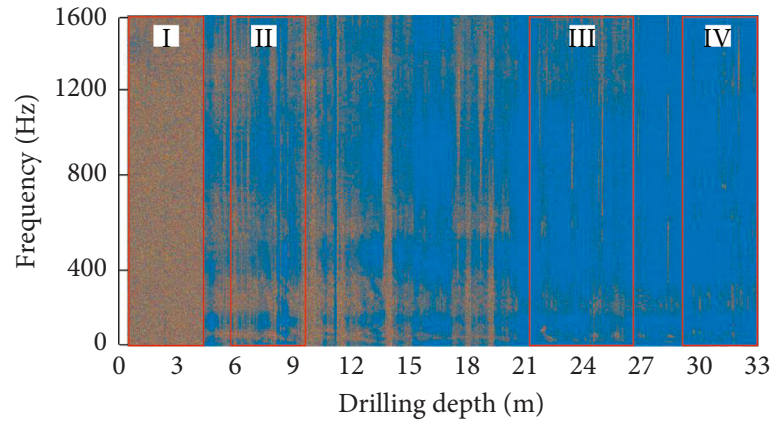

(a)

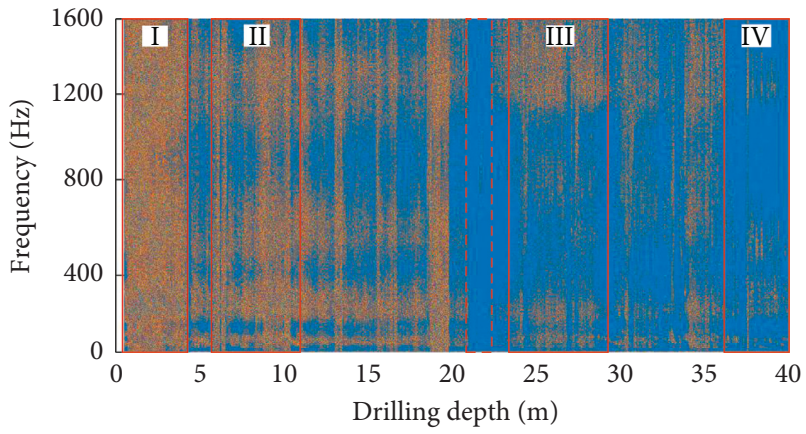

(b)

FIgURE 16: Spectrum distribution of the cross-layer boreholes: (a) borehole No. 11; (b) borehole No. 12.

$\omega(\tau-t)$ is the short-time analysis window, where $\tau$ is finite time.

STFT is carried out on the vibration signals. The spectrum distribution of the cross-layer boreholes is shown in Figure 16. At different depths, the frequency bands of the spectrum show different features. In Figure 16(a), in the range $I$, where the rock is sandstone with high strength, the vibration signal has both the most abundant spectrum and high energy intensity in the whole range of $0-1600 \mathrm{~Hz}$, while in the range IV, where the coal or weak rock is drilled, the energy mainly distributes in the low-frequency band (within $0-200 \mathrm{~Hz})$.
The spectrum distribution of the in-seam borehole is shown in Figure 17. It can be seen that the energy concentrates in quite narrow frequency bands around 200 and $600 \mathrm{~Hz}$. In particular, in the zone marked with dashed line in Figures 16(b) and 17, there is much less energy distributing in all the frequency, which indicates that the drilled rock mass or coal is loose. The results are consistent with those in the literature $[39,40]$.

From the spectrum distribution, it is difficult to give quantitative evaluation for the geological condition. However, based on the observation of all the tested signals, a primary standard for classifying the rock mass is proposed 


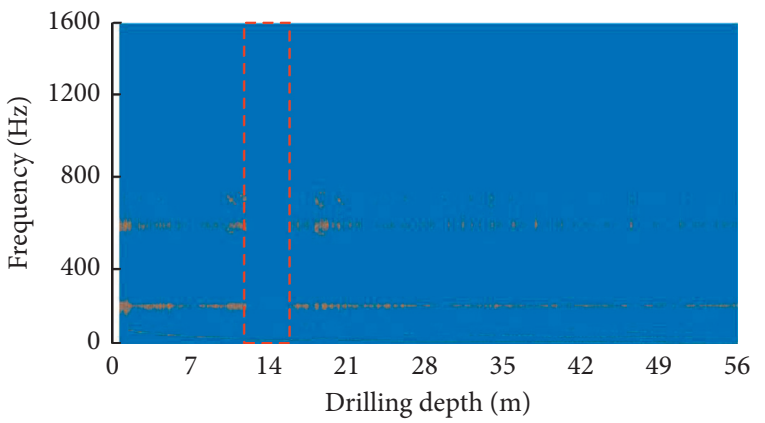

Figure 17: Spectrum distribution of the in-seam borehole No. 22.

TABLE 4: Rock mass classification based on the spectrum energy distribution.

\begin{tabular}{|c|c|c|c|}
\hline \multirow{2}{*}{$\begin{array}{l}\text { Rock mass } \\
\text { classification }\end{array}$} & \multicolumn{3}{|c|}{ Frequency range } \\
\hline & $0-400 \mathrm{~Hz}$ & $400-800 \mathrm{~Hz}$ & $800-1600 \mathrm{~Hz}$ \\
\hline I & $\begin{array}{l}\text { High energy distributes in the entire } \\
\text { frequency range }\end{array}$ & $\begin{array}{l}\text { High energy distributes in the entire } \\
\text { frequency range }\end{array}$ & $\begin{array}{l}\text { High energy distributes in the entire } \\
\text { frequency range }\end{array}$ \\
\hline II & $\begin{array}{l}\text { Energy is weaker than Class I and } \\
\text { mainly distributes within } 250-350 \mathrm{~Hz}\end{array}$ & $\begin{array}{l}\text { Energy is weaker than Class I and } \\
\text { mainly distributes within } 500-700 \mathrm{~Hz}\end{array}$ & $\begin{array}{l}\text { Energy is weaker than Class I and } \\
\text { mainly distributes within } \\
1100-1300 \mathrm{~Hz}\end{array}$ \\
\hline III & $\begin{array}{c}\text { Energy is weak and mainly distributes } \\
\text { within } 0-200 \mathrm{~Hz}\end{array}$ & $\begin{array}{c}\text { There is no obvious spectrum } \\
\text { distribution }\end{array}$ & $\begin{array}{c}\text { Energy is weak and mainly distributes } \\
\text { within } 1200-1600 \mathrm{~Hz}\end{array}$ \\
\hline IV & $\begin{array}{c}\text { Energy is weak and mainly distributes } \\
\text { within } 0-200 \mathrm{~Hz}\end{array}$ & $\begin{array}{l}\text { There is no obvious spectrum } \\
\text { distribution }\end{array}$ & $\begin{array}{l}\text { There is no obvious spectrum } \\
\text { distribution }\end{array}$ \\
\hline
\end{tabular}
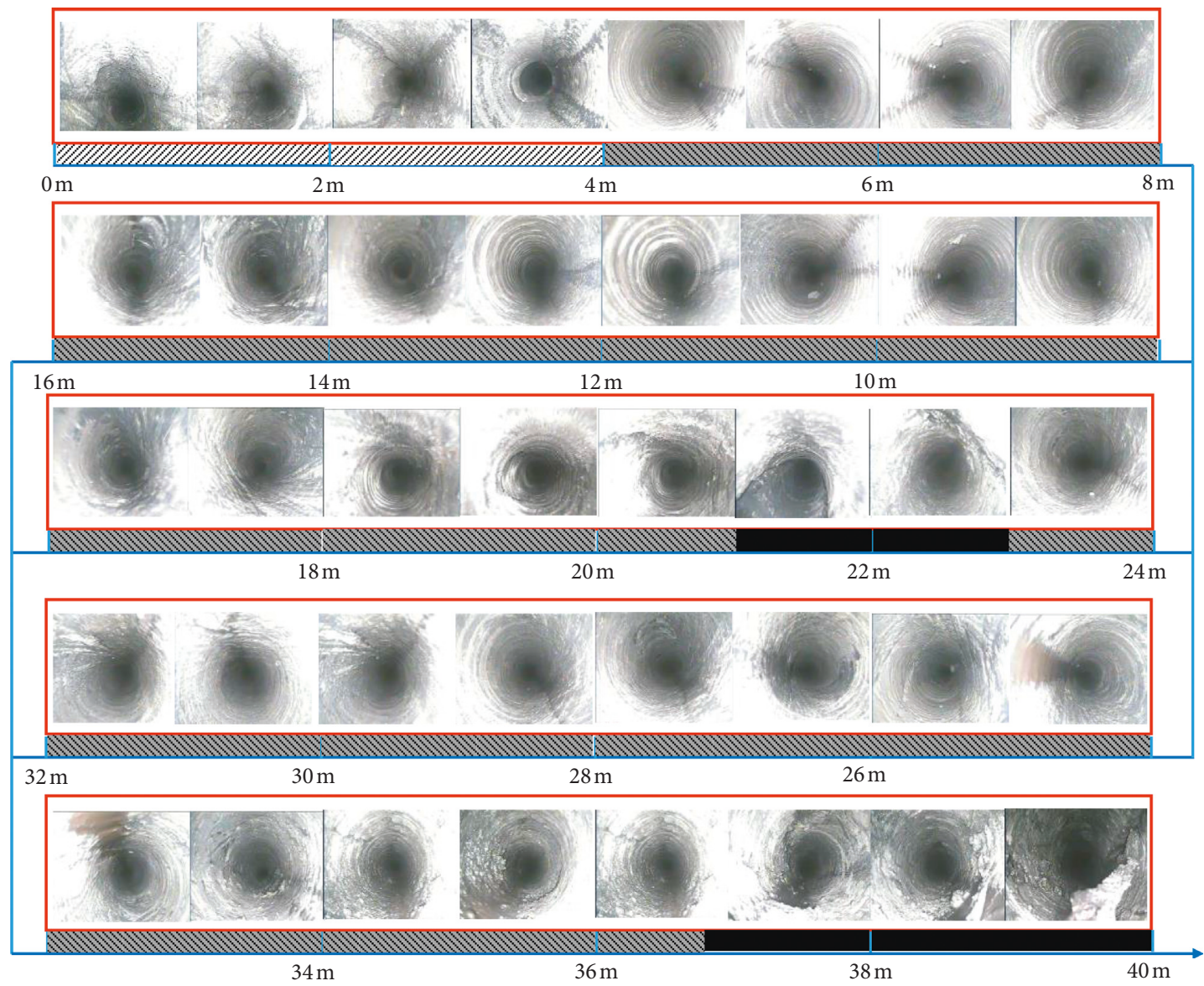

데라 I

II \& III

IV

Figure 18: Photos of borehole No. 12 at different depths. 


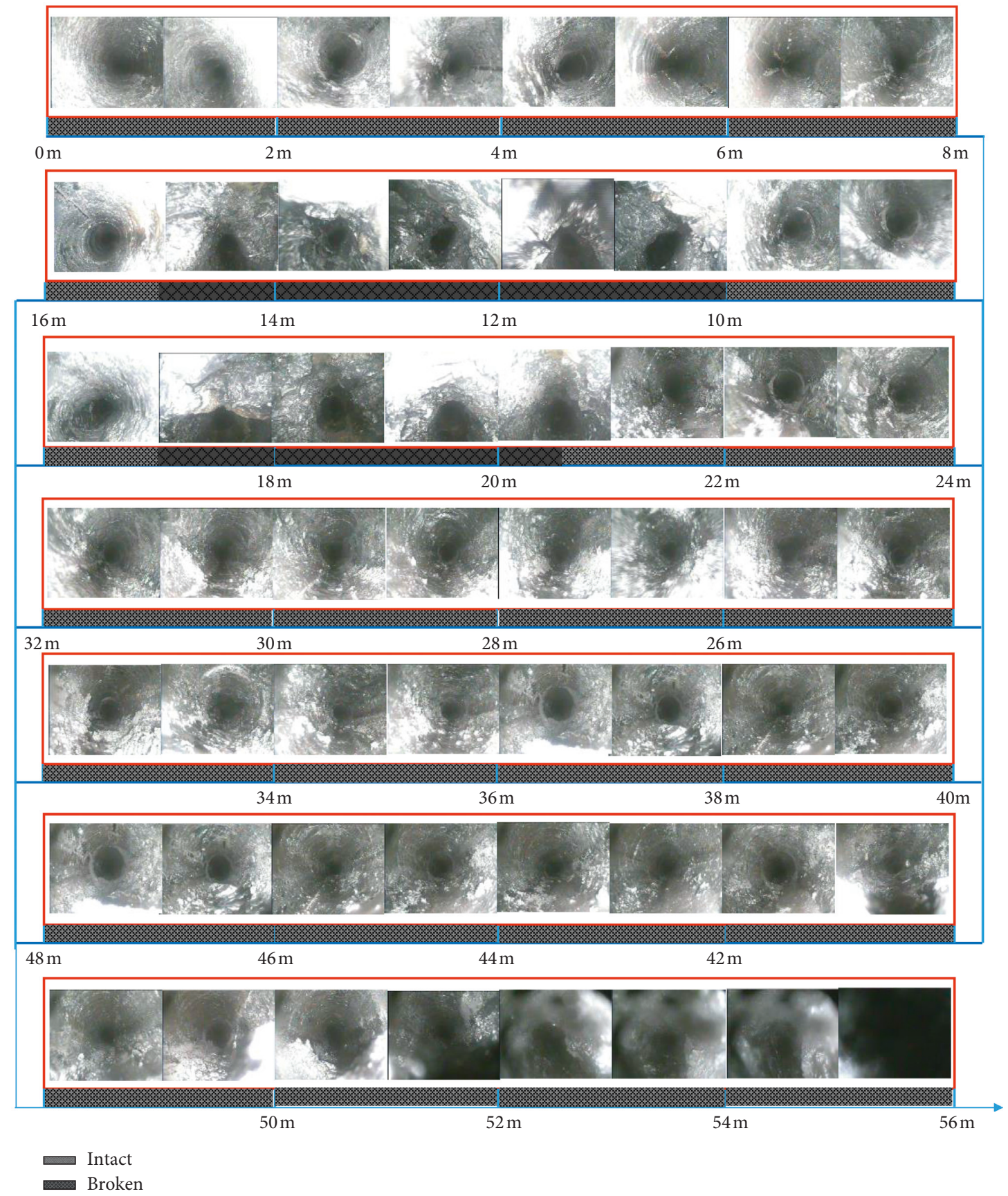

Figure 19: Photos of borehole No. 22 at different depths.

and listed in Table 4. The information in Table 4 can be a supplement for the MWD system or the time-domain analysis in the VMWD system.

\section{Results of Borehole Camera Detecting}

5.1. Cross-Layer Borehole. As the borehole camera testing is time-consuming and difficult to be carried out in deep boreholes, only portion of the tested boreholes was detected using the camera system. The photos of borehole No. 12 at different depths are shown in Figure 18. The state of rock mass can be distinguished based on the photos. For example, around the depths of 0 to $4 \mathrm{~m}$, the rock appears quite intact, while around the depth of $22 \mathrm{~m}$, the rock shows clearly broken characteristic. However, limited by the resolution of the photos, it is difficult to classify the state of rock mass into four categories, as in the MWD and VMWD systems. After some attempts, the rock mass along the cross-layer boreholes is classified into three categories, which is intact, less intact, and broken. For the intact zone, the wall of the borehole is smooth and with little fracture. For the less intact zone, the wall of the borehole has thread-shaped texture and some 


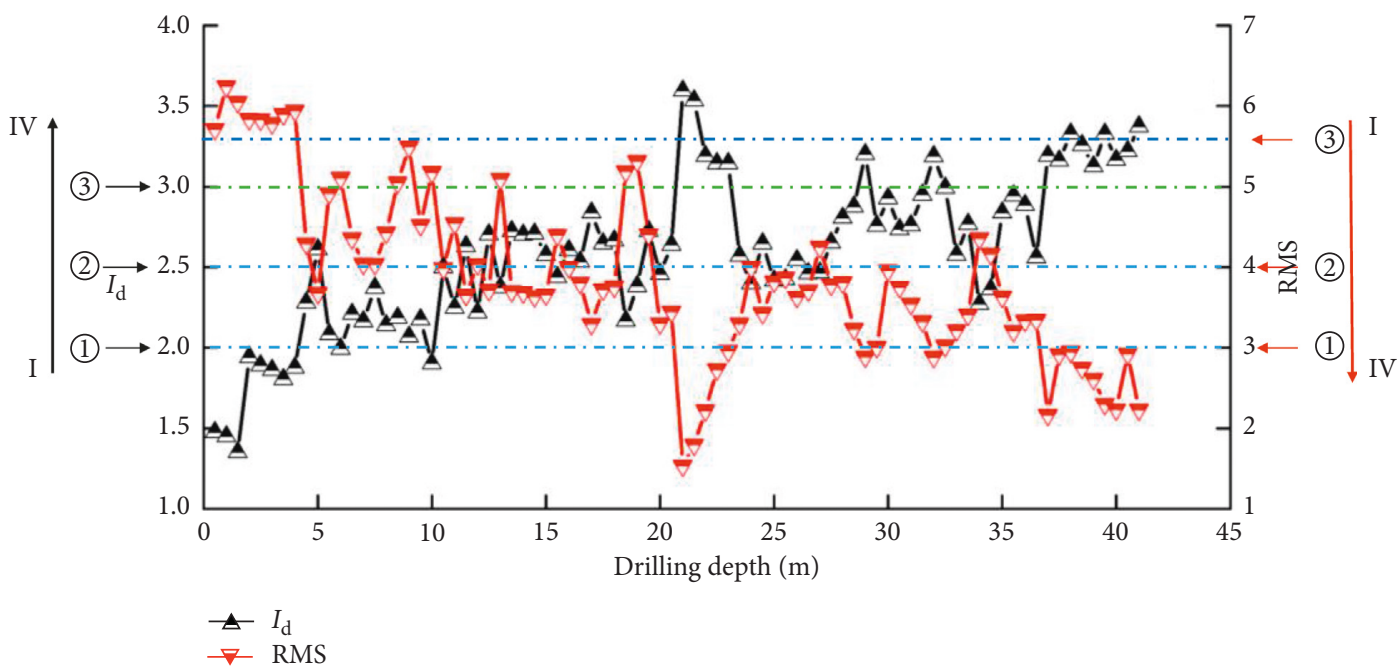

(a)

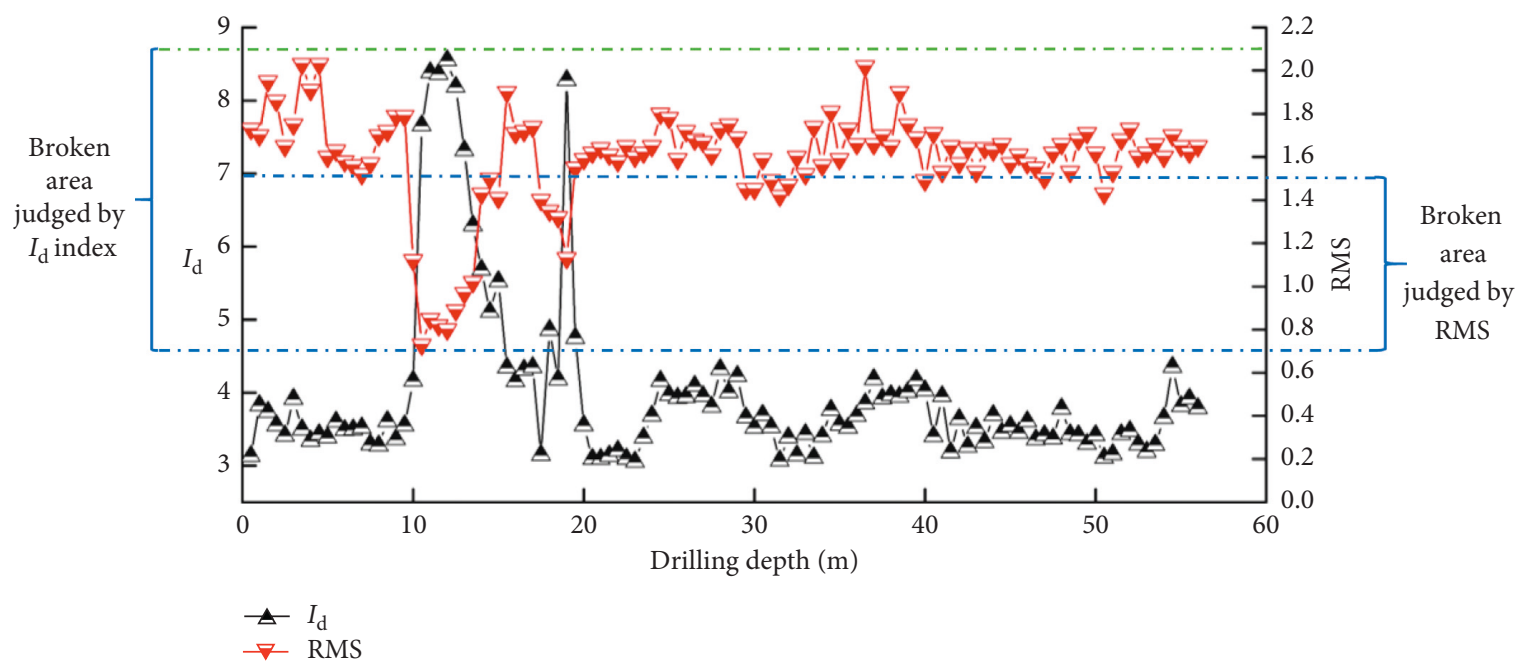

(b)

Figure 20: Comparison of the results of MWD and VMWD systems. (a) Cross-layer borehole No. 12. (b) In-seam borehole No. 22.

TABLE 5: Rock mass classification results of MWD and VMWD systems of cross-layer borehole No. 12.

\begin{tabular}{lcc}
\hline Rock classification & The $I_{\mathrm{d}}$ value divides the result & The RMS value divides the result \\
I & $0 \sim 4.2 \mathrm{~m}$ & $0 \sim 4.1 \mathrm{~m}$ \\
II & $4.2 \mathrm{~m} \sim 13.2 \mathrm{~m}$ & $4.1 \mathrm{~m} \sim 13.3 \mathrm{~m}$ \\
III & $13.2 \mathrm{~m} \sim 18.1 \mathrm{~m}$ & $13.3 \mathrm{~m} \sim 18 \mathrm{~m}$ \\
II & $18.1 \mathrm{~m} \sim 20.7 \mathrm{~m}$ & $18 \mathrm{~m} \sim 20.7 \mathrm{~m}$ \\
IV & $20.7 \mathrm{~m} \sim 23.1 \mathrm{~m}$ & $20.7 \mathrm{~m} \sim 23 \mathrm{~m}$ \\
III & $23.1 \mathrm{~m} \sim 36.6 \mathrm{~m}$ & $23 \mathrm{~m} \sim 36.5 \mathrm{~m}$ \\
IV & $36.6 \mathrm{~m} \sim 41 \mathrm{~m}$ & $36.5 \mathrm{~m} \sim 41 \mathrm{~m}$ \\
\hline
\end{tabular}

TABLE 6: Rock mass classification results of MWD and VMWD systems of in-seam borehole No. 22.

\begin{tabular}{lcc}
\hline Rock classification & The $I_{\mathrm{d}}$ value divides the result & The RMS value divides the result \\
\hline Intact & $0 \sim 10 \mathrm{~m}$ & $0 \sim 10.2 \mathrm{~m}$ \\
Broken & $10 \mathrm{~m} \sim 15.4 \mathrm{~m}$ & $10.2 \mathrm{~m} \sim 15.1 \mathrm{~m}$ \\
Intact & $15.4 \mathrm{~m} \sim 17.5 \mathrm{~m}$ & $15.1 \mathrm{~m} \sim 17.3 \mathrm{~m}$ \\
Broken & $17.5 \mathrm{~m} \sim 19.6 \mathrm{~m}$ & $17.3 \mathrm{~m} \sim 20 \mathrm{~m}$ \\
Intact & $19.6 \mathrm{~m} \sim 56 \mathrm{~m}$ & $20 \mathrm{~m} \sim 56 \mathrm{~m}$ \\
\hline
\end{tabular}



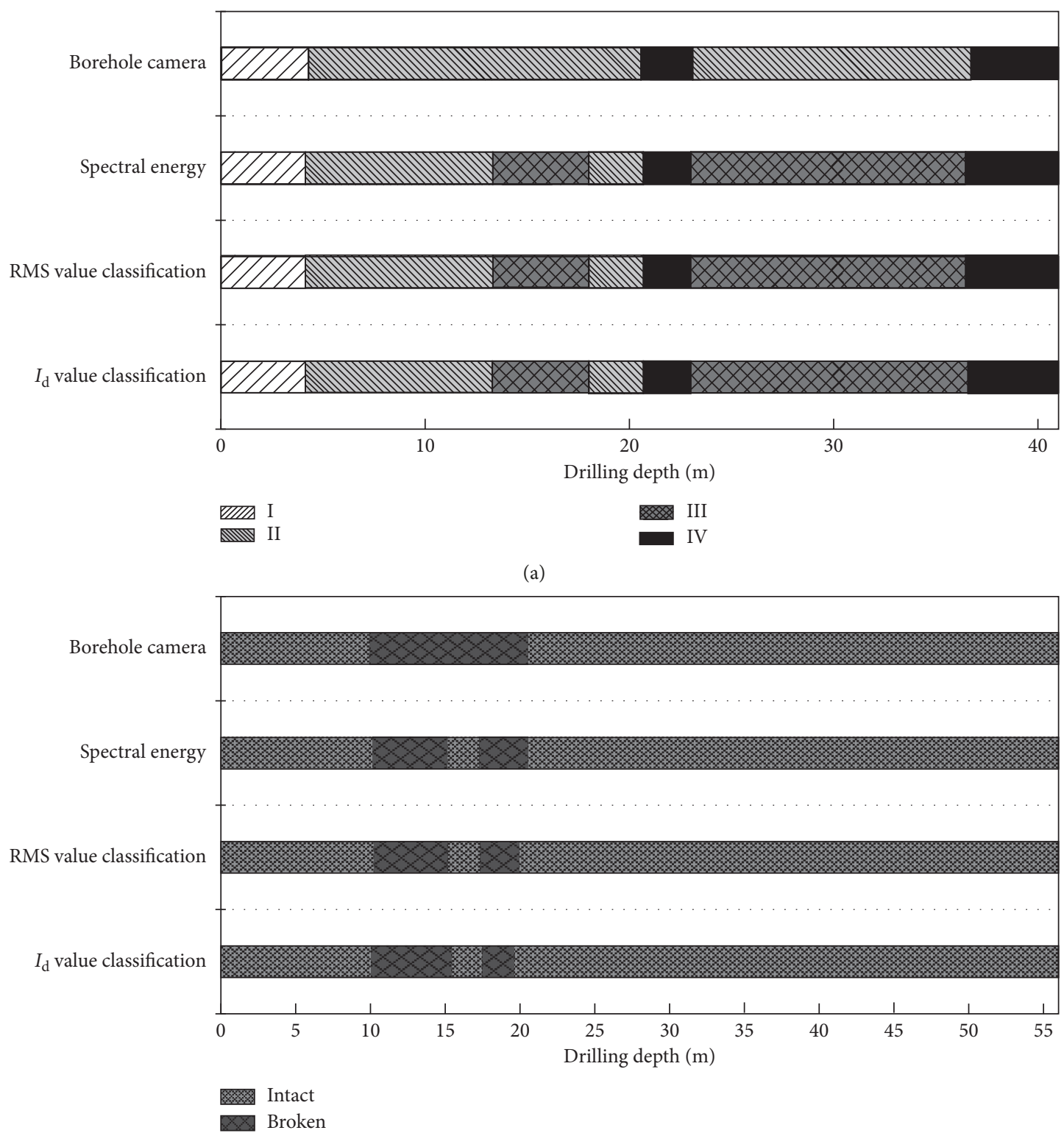

(b)

Figure 21: Comprehensive analysis and comparison between different methods.

fractures. For the broken rock, there are considerable fractures. In order to compare the results with those of MWD and VMWD systems, the intact zone is considered to be I category, while the less intact zone is considered to be II and III categories. The classification results are shown in Figure 18.

5.2. In-Seam Borehole. Figure 19 shows the borehole camera detecting results of the in-seam borehole No. 22. It can be seen that the failure of the surrounding rock is more serious and the integrity is weaker than that in the cross-layer boreholes. This is due to the low hardness of the coal in Yangliu coal mine. Based on the photos at different depths, the coal is distinguished into two categories, i.e., intact and broken. For the intact coal, the wall of the borehole is smooth with some fractures, while, for the broken coal, there are many fractures and the deformation of the wall is considerable. The classification results are shown in Figure 19.

It should be pointed out that when drilling to the depth of approximately $54 \mathrm{~m}$ in borehole No. 22, the cinder in the hole could not be completely discharged as for the large deformation of the coal. Then, the camera was blocked and the geological condition of rock mass inside the borehole could not be properly photographed.

\section{Comprehensive Analysis and Comparison between Different Methods}

Comparison between different methods is carried out. Taking the cross-layer borehole No. 12 and in-seam borehole No. 22 for an example, we give the curves of the index $I_{\mathrm{d}}$ 
from the MWD system and the RMS from the VMWD system in Figure 20 for the cross-layer and in-seam boreholes. The classification criterions are shown in the figure. Due to the different definitions of the variables, the $I_{\mathrm{d}}$ values increase along the depth of the borehole, while the RMS values decrease. The two variables show a remarkable negative correlation. Therefore, the rock mass classification results from the two systems (listed in Tables 5 and 6) are generally consistent.

In Figure 21, the classification of the rock mass along the cross-layer borehole No. 12 and in-seam borehole No. 22 is visualized. It can be seen that the results from the four methods are comparable. In practice, the MWD system is the most feasible method to be implemented, while the VMWD system can provide the information on the borehole trajectory simultaneously. As for the borehole camera system, direct information about the rock lithology can be captured. Therefore, according to the requirement of the engineering, part or all of the methods involved in the present study can be adopted to give specific geological conditions.

\section{Conclusions}

To determine the geological condition in the underground coal mines, comprehensive real-time methods are tested in the present study, which are MWD system, VMWD system, and borehole camera system. The drilling process of crosslayer and in-seam boreholes is monitored. The main conclusions are as follows:

(1) In the MWD system, the operating parameters of the drilling machine are recorded. Based on the collected parameters, a rock drillability index $I_{\mathrm{d}}$ is used to classify the rock mass condition. For the monitored cross-layer boreholes, the states of rock mass and coal are divided into four categories, while, for the in-seam borehole, the state of coal is divided into two types.

(2) In the VMWD system, the vibration of the drilling bit is monitored. The signals are analyzed in both time domain and frequency domain. In the time domain, a quantitative classification criterion for rock mass condition is proposed based on the root mean square value of the signal, while, in the frequency domain, a qualitative estimate on the rock mass condition is put forward based on the energy of the spectrum.

(3) Comprehensive compassion between the results from MWD, VMWD, and borehole camera system is carried out. The results show that both the MWD system and the VMWD system can provide valuable information for geological conditions, and the outcomes of different methods are generally comparable.

\section{Data Availability}

The data used to support the findings of this study are included within the article.

\section{Conflicts of Interest}

The authors declare that they have no conflicts of interest.

\section{Acknowledgments}

This work was supported by the Fundamental Research Funds for the Central Universities (Grant no. Z19012).

\section{References}

[1] S. D. Carrière, K. Chalikakis, G. Sénéchal, C. Danquigny, and C. Emblanch, "Combining electrical resistivity tomography and ground penetrating radar to study geological structuring of karst unsaturated zone," Journal of Applied Geophysics, vol. 94, pp. 31-41, 2013.

[2] T. Mochales, A. M. Casas, E. L. Pueyo et al., "Detection of underground cavities by combining gravity, magnetic and ground penetrating radar surveys: a case study from the zaragoza area, NE Spain,” Environmental Geology, vol. 53, no. 5, pp. 1067-1077, 2007.

[3] S. Wänstedt, S. Carlsten, and S. Tirén, "Borehole radar measurements aid structure geological interpretations," Journal of Applied Geophysics, vol. 43, no. 2-4, pp. 227-237, 2000.

[4] M. Löfgren and I. Neretnieks, "Formation factor logging by electrical methods," Journal of Contaminant Hydrology, vol. 61, no. 1-4, pp. 107-115, 2003.

[5] Y. Lu, Y. Liu, X. Li, and Y. Kang, "A new method of drilling long boreholes in low permeability coal by improving its permeability," International Journal of Coal Geology, vol. 84, no. 2, pp. 94-102, 2010.

[6] C. Zheng, Z. Chen, M. Kizil, S. Aminossadati, Q. Zou, and P. Gao, "Characterisation of mechanics and flow fields around in-seam methane gas drainage borehole for preventing ventilation air leakage: a case study," International Journal of Coal Geology, vol. 162, pp. 123-138, 2016.

[7] Y. Xin and L. Mu, "Analysis of instability characteristics of surrounding rocks in mudstone roof gateway subjected to high stress and its control," Journal of Mining \& Safety Engineering, vol. 34, pp. 519-526, 2017.

[8] J. Chen and Z. Q. Yue, "Ground characterization using breaking-action-based zoning analysis of rotary-percussive instrumented drilling," International Journal of Rock Mechanics and Mining Sciences, vol. 75, pp. 33-43, 2015.

[9] J. Chen and Z. Q. Yue, "Weak zone characterization using full drilling analysis of rotary-percussive instrumented drilling," International Journal of Rock Mechanics and Mining Sciences, vol. 89, pp. 227-234, 2016.

[10] P. Li, H. Zhang, S. Jiang, and W. Zhang, "Analysis and testing of load characteristics for rotary-percussive drilling of lunar rock simulant with a lunar regolith coring bit," Shock and Vibration, vol. 2017, Article ID 3012749, 15 pages, 2017.

[11] Z. Li, L. Zhu, W. Yin, and Y. Song, "Study on monitoring rock burst through drill pipe torque," Shock and Vibration, vol. 2015, Article ID 371948, 8 pages, 2015.

[12] W. Liu, J. Rostami, and E. Keller, "Application of new void detection algorithm for analysis of feed pressure and rotation pressure of roof bolters," International Journal of Mining Science and Technology, vol. 27, no. 1, pp. 77-81, 2017.

[13] Q. Wang, H. Gao, H. Yu, B. Jiang, and B. Liu, "Method for measuring rock mass characteristics and evaluating the grouting-reinforced effect based on digital drilling," Rock 
Mechanics and Rock Engineering, vol. 52, no. 3, pp. 841-851, 2018.

[14] Z. Q. Yue, C. F. Lee, K. T. Law, and L. G. Tham, "Automatic monitoring of rotary-percussive drilling for ground characterization-illustrated by a case example in Hong Kong," International Journal of Rock Mechanics and Mining Sciences, vol. 41, no. 4, pp. 573-612, 2004.

[15] K. Zhang, K. Sun, B. Yu, and R. P. Gamage, "Determination of sealing depth of in-seam boreholes for seam gas drainage based on drilling process of a drifter," Engineering Geology, vol. 210, pp. 115-123, 2016.

[16] J. Navarro, J. A. Sanchidrián, P. Segarra, R. Castedo, E. Costamagna, and L. M. López, "Detection of potential overbreak zones in tunnel blasting from MWD data," Tunnelling and Underground Space Technology, vol. 82, pp. 504516, 2018.

[17] M. Capik, A. O. Yilmaz, and S. Yasar, "Relationships between the drilling rate index and physicomechanical rock properties," Bulletin of Engineering Geology and the Environment, vol. 76, no. 1, pp. 253-261, 2016.

[18] S. Kahraman, "Rotary and percussive drilling prediction using regression analysis," International Journal of Rock Mechanics and Mining Sciences, vol. 36, no. 7, pp. 981-989, 1999.

[19] A. Patel, "Characterization of cavities in rocks using drilling parameters," International Journal of Rock Mechanics and Mining Sciences, vol. 63, pp. 122-130, 2013.

[20] Z. Tan, M. Cai, Z. Yue, L. G. Tham, and C. F. Lee, "Interface identification of intricate weathered granite ground investigation in Hong Kong using drilling parameters," Chinese Journal of Rock Mechanics \& Engineering, vol. 25, pp. 29392945, 2006.

[21] S. Liu, Y. Feng, and D. Liu, "Numerical experiments of dynamic response characteristics of rock drilling on stratified roof in coal roadway," Chinese Journal of Rock Mechanics \& Engineering, vol. 33, pp. 3170-3176, 2014.

[22] T. Saksala, D. Gomon, M. Hokka, and V.-T. Kuokkala, "Numerical and experimental study of percussive drilling with a triple-button bit on kuru granite," International Journal of Impact Engineering, vol. 72, pp. 56-66, 2014.

[23] O. Su and N. A. Akcin, "Numerical simulation of rock cutting using the discrete element method," International Journal of Rock Mechanics and Mining Sciences, vol. 48, no. 3, pp. 434-442, 2011.

[24] P. Hatherly, R. Leung, S. Scheding, and D. Robinson, "Drill monitoring results reveal geological conditions in blasthole drilling," International Journal of Rock Mechanics and Mining Sciences, vol. 78, pp. 144-154, 2015.

[25] X. He and C. Xu, "Specific energy as an index to identify the critical failure mode transition depth in rock cutting," Rock Mechanics and Rock Engineering, vol. 49, no. 4, pp. 1461-1478, 2015.

[26] R. Leung and S. Scheding, "Automated coal seam detection using a modulated specific energy measure in a monitorwhile-drilling context," International Journal of Rock Mechanics and Mining Sciences, vol. 75, pp. 196-209, 2015.

[27] S.-C. Li, Y.-G. Xue, H. Tian et al., "Identifying the geological interface of the stratum of tunnel granite and classifying rock mass according to drilling energy theory," Arabian Journal of Geosciences, vol. 9, no. 1, pp. 49-61, 2015.

[28] H. Munoz, A. Taheri, and E. K. Chanda, "Rock drilling performance evaluation by an energy dissipation based rock brittleness index," Rock Mechanics and Rock Engineering, vol. 49, no. 8, pp. 3343-3355, 2016.
[29] R. Teale, "The concept of specific energy in rock drilling," International Journal of Rock Mechanics and Mining Sciences \& Geomechanics Abstracts, vol. 2, no. 1, pp. 57-73, 1965.

[30] K. Zhang, R. Hou, G. Zhang, G. Zhang, and H. Zhang, "Rock drillability assessment and lithology classification based on the operating parameters of a drifter: case study in a coal mine in China," Rock Mechanics and Rock Engineering, vol. 49, no. 1, pp. 329-334, 2015.

[31] H. Basarir, L. Tutluoglu, and C. Karpuz, "Penetration rate prediction for diamond bit drilling by adaptive neuro-fuzzy inference system and multiple regressions," Engineering Geology, vol. 173, pp. 1-9, 2014.

[32] B. Rajesh Kumar, H. Vardhan, M. Govindaraj, and G. S. Vijay, "Regression analysis and ann models to predict rock properties from sound levels produced during drilling," International Journal of Rock Mechanics and Mining Sciences, vol. 58, pp. 61-72, 2013.

[33] O. Saeidi, S. R. Torabi, and M. Ataei, "Prediction of the rock mass diggability index by using fuzzy clustering-based, ann and multiple regression methods," Rock Mechanics and Rock Engineering, vol. 47, no. 2, pp. 717-732, 2013.

[34] B. Tiryaki, "Predicting intact rock strength for mechanical excavation using multivariate statistics, artificial neural networks, and regression trees," Engineering Geology, vol. 99, no. 1-2, pp. 51-60, 2008.

[35] J.-S. Gao, J.-M. Sun, Y.-J. Jiang, P.-Y. Zhang, and J. Wu, "Weighted processing for microresistivity imaging logging in oil-based mud using a support vector regression model," Geophysics, vol. 82, no. 6, pp. D341-D351, 2017.

[36] Z. Qin, H. Pan, Z. Wang et al., "A fast forward algorithm for real-time geosteering of azimuthal gamma-ray logging," Applied Radiation and Isotopes, vol. 123, pp. 114-120, 2017.

[37] J. Sun, J. Gao, Y. Jiang, and L. Cui, "Resistivity and relative permittivity imaging for oil-based mud: a method and numerical simulation," Journal of Petroleum Science and Engineering, vol. 147, pp. 24-33, 2016.

[38] C. Yuan, C. Zhou, F. Zhang, S. Hu, and C. Li, “A novel method for quantitative geosteering using azimuthal gamma-ray logging," Applied Radiation and Isotopes, vol. 96, pp. 63-70, 2015.

[39] S. Kahraman, J. Rostami, and A. Naeimipour, "Review of ground characterization by using instrumented drills for underground mining and construction," Rock Mechanics and Rock Engineering, vol. 49, no. 2, pp. 585-602, 2015.

[40] J. Rostami, S. Kahraman, A. Naeimipour, and C. Collins, "Rock characterization while drilling and application of roof bolter drilling data for evaluation of ground conditions," Journal of Rock Mechanics and Geotechnical Engineering, vol. 7, no. 3, pp. 273-281, 2015. 


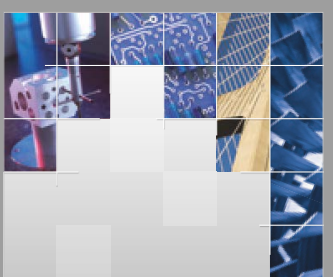

\section{Enfincering}
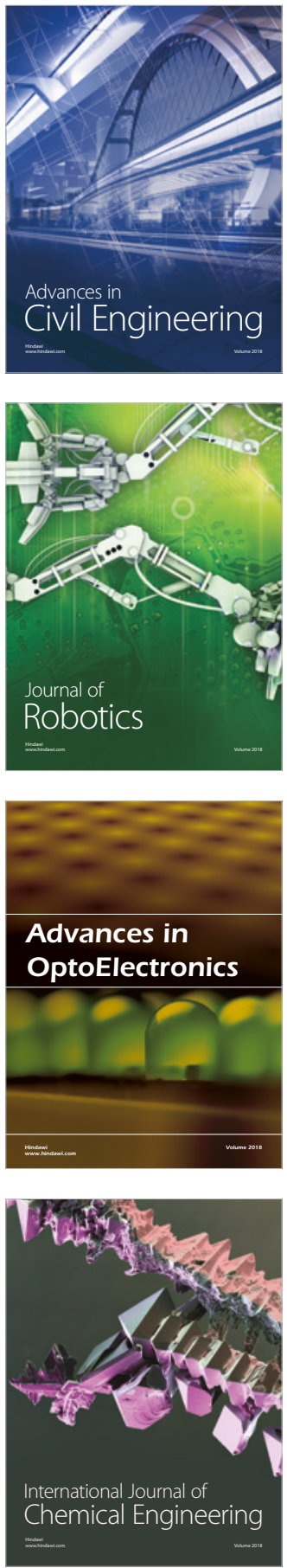

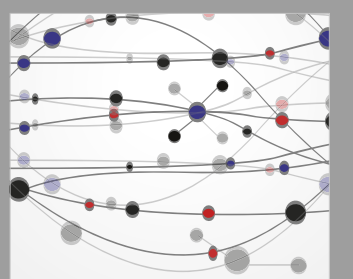

\section{Rotating \\ Machinery}

The Scientific World Journal

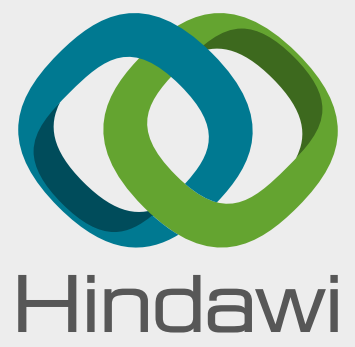

Submit your manuscripts at

www.hindawi.com
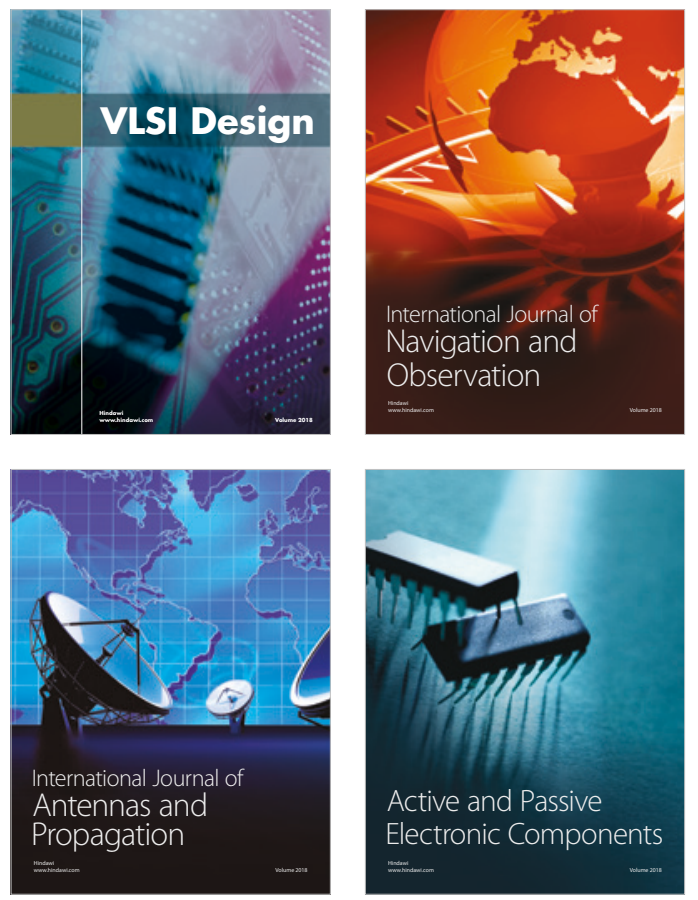
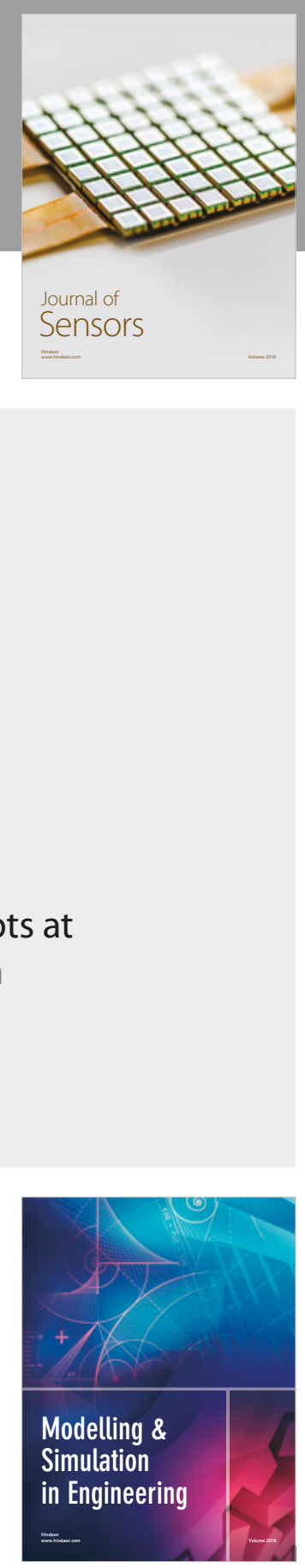

\section{Advances \\ Multimedia}
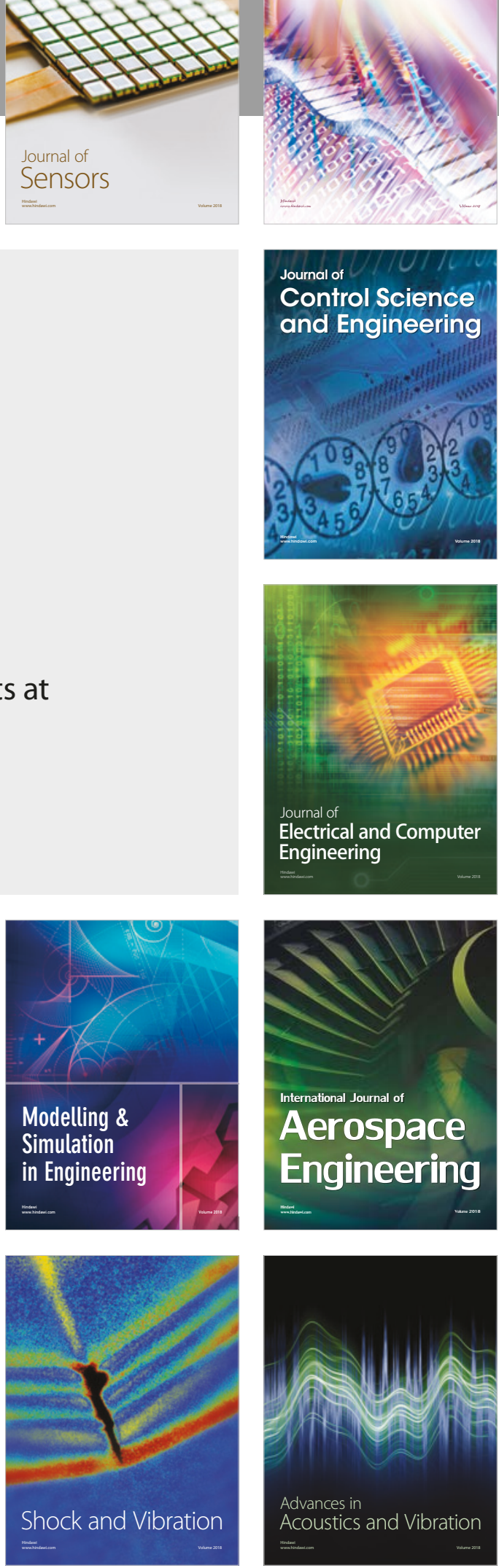